\title{
Experimental study on the coefficient of restitution of grain against block interfaces for natural and engineered materials
}

\author{
C.S. Sandeep ${ }^{1}$, K. Senetakis ${ }^{2 *}$, D. Cheung ${ }^{3}$ and C.E. Choi ${ }^{4}$, Y. Wang ${ }^{5}$, M.R. Coop ${ }^{6}$, \\ C.W.W. $\mathrm{Ng}^{7}$
}

\section{Author information:}

${ }^{1}$ C.S. Sandeep, Civil Eng., MTech, PhD student

Department of Architecture and Civil Engineering

City University of Hong Kong, Kowloon, Hong Kong SAR China

Email: sschitta2-c@my.cityu.edu.hk

${ }^{2}$ K. Senetakis, Civil Eng., MSc, PhD, Assistant Professor

Department of Architecture and Civil Engineering

Yeung Kin Man Academic Building, Blue Zone 6/F

City University of Hong Kong, Kowloon, Hong Kong SAR China

Email: ksenetak@ cityu.edu.hk, Tel: +852 34424312

* (corresponding author)

\author{
${ }^{3}$ D. K. H. Cheung, BSc, PhD student \\ Department of Civil and Environmental Engineering \\ Hong Kong University of Science and Technology, Hong Kong SAR China \\ Email: khcheungal@ connect.ust.hk
}


${ }^{4}$ C.E. Choi, BSc., PhD, Research Assistant Professor

Department of Civil and Environmental Engineering

The Hong Kong University of Science and Technology, Hong Kong SAR China

HKUST Fok Ying Tung Graduate School, Nansha, Guangzhou

Junior Fellow

The HKUST Jockey Club Institute for Advanced Study

Email: ceclarence@ust.hk

${ }^{5}$ Y. Wang, Civil Eng., MSc, PhD, Associate Professor

Department of Architecture and Civil Engineering

City University of Hong Kong, Kowloon, Hong Kong SAR China

Email: yuwang@cityu.edu.hk

${ }^{6}$ M.R. Coop, Civil Eng., PhD, Professor

Department of Civil, Environmental and Geomatic Engineering

University College London, London, UK.

Email: $\underline{\text { m.coop@ucl.ac.uk }}$

${ }^{7}$ C.W.W. Ng, BSc., PhD, Chair Professor

Department of Civil and Environmental Engineering

The Hong Kong University of Science and Technology, Hong Kong SAR China

Email: cecwwng@ust.hk 


\begin{abstract}
The coefficient of restitution (COR) is an important input parameter in the numerical simulation of granular flows, as it governs the travel distance, the lateral spreading and the design of barriers. In this study, a new custom-built micro-mechanical impact loading apparatus is presented along with impact experiments on engineered and natural materials. The COR and energy loss of various grains and base block combinations are studied, including fairly regular shaped Leighton Buzzard sand (LBS) grains as a natural soil and granite/rubber as base blocks, apart from the use of engineered materials for the grains (chrome steel balls, glass balls) and blocks (stainless steel, brass). The repeatability of the new micro-mechanical impact loading apparatus was checked by impacting chrome steel balls on stainless steel block. In all the test combinations, the higher and lower values of the COR are found for granite block (ranging between 0.75-0.95) and rubber block (ranging between 0.37-0.44) combinations, respectively. For the tested grain-block combinations, lower values of COR were observed for impacts between materials of low values of composite Young's modulus. However, within the narrow range of composite surface roughness of the tested grain-block interfaces no particular trend was observed in the COR values. Compared to glass balls and chrome steel balls, greater scatter in the COR values is observed for natural sand grains. This is due to the variation of the elastic and morphological characteristics among individual LBS grains.
\end{abstract}

Keywords: Coefficient of restitution; Energy loss; Impact velocity; Laboratory test; Sand grains 


\section{Nomenclature}

$\alpha$

$\delta_{\mathrm{N}}$

$\mathrm{a}, \mathrm{b}$

C

COR

$\% \Delta \mathrm{D}$

$\mathrm{E}_{\mathrm{s}}$ and $\mathrm{E}_{\mathrm{b}}$

$\mathrm{E}^{*}$

$\mathrm{F}_{\mathrm{N}}$

$\mathrm{F}_{\mathrm{D} 1}$ and $\mathrm{F}_{\mathrm{D} 2}$

g

$\mathrm{h}_{1}$ and $\mathrm{h}_{2}$

$\mathrm{m}_{\mathrm{s}}$

$\mathrm{R}$

$\mathrm{S}_{\mathrm{q}}$

$\mathrm{V}_{1 \mathrm{~s}}$ and $\mathrm{V}_{1 \mathrm{~b}}$

$\mathrm{V}_{2 \mathrm{~s}}$ and $\mathrm{V}_{2 \mathrm{~b}}$

$v_{\mathrm{s}}$ and $v_{\mathrm{b}}$

GB

CSB

LBS
Contact radius

Normal displacement

Number of points in horizontal plane

Deviation of each point from mean value

Coefficient of restitution

Energy loss percentage

Elastic modulus of the grain and block

Composite Young's modulus

Applied normal force

Air drag on grain

Acceleration due to gravity

Initial and rebound height of the grain

Mass of grain

Radius of the grain

RMS roughness

Velocity of grain and block before impact

Velocity of grain and block after impact

Poisson's ratio of the grain and block materials

Glass ball

Chrome steel ball

Leighton Buzzard sand 


\section{Introduction}

The collision behaviour between grains or grains with solid objects is of interest in various areas of geotechnical and geological engineering research, such as rock falls, landslides, debris flows, sand dunes, volcanic eruptions, seismic hazards and meteoritic impacts (Gischig et al., 2015, Dufek et al., 2012, Jiang et al., 2018, Asteriou et al., 2012, Durda et al., 2011, Choi et al., 2014, Li and Zhao, 2018). Debris flows and rock falls generally occur in mountainous terrain and they cause uncountable loss of life and property. Hong Kong has a steep terrain and debris flows can travel long distances causing loss of life and destroying infrastructure, earthworks and disturbing traffic (Pun et al., 2011). Debris flows are rapid flows of predominantly coarse grained material with/without water mixtures which are generally started by a landslide. These flows often consist of processes which include initiation, flow and deposition (Chen and Lee, 2000). Due to their complex nature, debris flows generally cannot be studied by the traditional soil mechanics methods. There are two common approaches to study the behaviour of debris flows. First is through rheological approach and the other method is through coupled DEM/CFD analysis. In debris flows at the microscale, the particle dynamics involve exchange of momentum due to inertial granular collisions, friction between grains, viscous shear and solid fluid interactions (Iverson, 1997, Sanvitale and Bowman, 2016). In general, the mobilized blocks during flows/rock falls move down the slope due to gravity with a subsequent impact and rebound (Ritchie, 1963, Paronuzzi, 1989).

The Discrete element method, DEM (Cundall and Strack, 1979) helps to generate useful information about granular flow behaviour due to its capabilities in capturing large particle displacements (Calvetti and Nova, 2004). In DEM, researchers use input parameters alongside theoretical models to simulate the particle contacts; one approach is to use contact stiffnesses along with inter-particle friction (e.g., Cheung et al., 2013) and a second common 
approach is to use coefficient of restitution (COR) values (Garcia et al., 2016, Coetzee, 2017). The COR parameter is used to understand the amount of initial kinetic energy retained post collision. Researchers use COR values in understanding the collision behaviour between grains and barriers. In the simulations of rock falls, both normal and tangential contact behaviour, and COR are needed as inputs, where different types of block movements can be modelled such as free falling, bouncing, rolling and sliding (Descoeudres and Zimmermann, 1987, Asteriou et al., 2012). Recent technical advancements have made it possible to obtain normal and tangential behaviour at the contacts of soil grains in the laboratory using interparticle loading apparatus (Cavarretta et al., 2011, Senetakis and Coop, 2014, Cole et al., 2010, Yang et al., 2016). However, relatively limited number of laboratory works has reported on the coefficient of restitution of natural sand grains impacting on blocks of variable material types.

Numerous DEM models simulating granular flows use COR in their analysis (Dahl et al., 2003, Clelland and Hrenya, 2002, Jasti and Higgs, 2010, Karolyi and Kertesz, 1998, Kozicki and Tejchman, 2005, Okura et al., 2000, Pfeiffer and Bowen 1989, Turmel and Locat, 2010, Makris and Roussos, 2000). Previous works have shown that the magnitude of the COR influences significantly the output of a numerical study, thus predictive tools in the study of granular flows need more systematic studies to investigate the behaviour of grains under collision (Mitchell and Hungr, 2016, Agliardi and Crosta, 2003, Di Prisco and Vecchiotti, 2006). However, the mechanism of impact between two bodies is a complex phenomenon as it involves short contact durations, and localization of stresses at the contacts which cause plastic deformations during impact (Aryaei et al., 2010). Earlier works stated that the COR values decrease with an increase in impact velocity (Thornton and Ning, 1998; Heibelmann et al., 2010, Brilliantov et al., 2007, Wong et al., 2009). In addition, previous experiments were also conducted to study spheres (or grains) colliding on block surfaces (Tabor, 1948, Kharaz 
and Gorham, 2000, Koller and Kolsky, 1987, Vincent, 1900, Reed, 1985, Sondergaard et al., 1990, Foerster et al., 1994, Lorenz et al., 1997, Marinack et al., 2013). However, most of the studies are limited to engineered spheres and block surfaces. Engineered materials like metals are highly homogeneous with microscopic flaws. By contrast, natural geological materials including soil grains and rocks/rock fragments, are not generally homogenous, they have internal flaws and their contacts are of brittle or elasto-plastic to brittle in nature (Cascante and Santamarina, 1996).

Yu and Tafti (2016) modelled the collision of micro size sand particles (around 0.1-0.2 mm in diameter) on engineered surfaces of stainless steel and aluminium and found that the COR value decreases with an increase in impact velocity. Durda et al. (2011), testing large granite spheres $(1 \mathrm{~m}$ in diameter) impacting each other at a speed on $1 \mathrm{~m} / \mathrm{s}$, obtained an average value of COR of 0.83. Imre et al. (2008) reported an average value of COR of 0.87 for steel balls of diameter $3 \mathrm{~mm}$ impacting on a conglomerate from a drop height of $20 \mathrm{~cm}$. It is noted that a limited amount of research is available comparing the impact behaviour between engineered materials and natural soil grains, such as quartz particles. Due to their irregular shape and internal defects, sand particles are difficult to test in the laboratory compared with perfect spheres. However, for the simulation of granular flows, it is important to obtain results, apart from perfect spheres using engineered grains, on natural sand grains.

In Hong Kong, debris flows occur most commonly in decomposed soils. The decomposed grains will be difficult to be tested because of their irregular shape, internal defects, multi mineral composition and presence of coating on their surfaces. In this preliminary study, we used regular shaped (high sphericity and high roundness) quartz sand grains of known surface roughness impacting on different types blocks, including granite and rubber, to obtain the COR values. Banks et al. (2005) evaluated the COR for quartz sand grains impacting on basalt surfaces to simulate the abrasion rates on Earth and Mars surfaces. They did not 
provide any information about the shape or the surface roughness and reported high scatter in the COR data (0.1-1). In static loading, Greenwood \& Tripp (1967) predicted that the surface roughness influences the loading behaviour in the normal direction which was later confirmed by recent experiments (Sandeep and Senetakis, 2018, Nardelli and Coop, 2018). Therefore, the surface roughness was quantified for the grains and blocks used in this study.

Additionally, in most of the previous studies the collision of grains on blocks has predominantly considered stiff surfaces with high Young's moduli. By contrast, there is limited information on the collisional behaviour against more flexible surfaces, such as rubber-type blocks. The implications of understanding the fundamental contact mechanics in terms of COR between grains and more flexible surfaces include improved estimates of the impact loads and therefore the optimization of barrier designs against flow-like landslides, such as, flexible type barriers or car tyre cushioning layers in front of concrete barriers (Lo, 2000).

This paper presents the main features of a new custom-built micro-mechanical impact loading apparatus developed by the authors. A custom-made dual-solenoid setup was used to hold grains with a size ranging from 1 to $3 \mathrm{~mm}$ in diameter. The current version of the apparatus allows experiments to be carried out on grains impacting on block surfaces for drop heights up to about 500mm. A high-speed photography technique was used to capture the drop and rebound heights. The COR of chrome steel balls (CSB) was studied initially to check the repeatability of the results. Subsequently, the COR and energy loss of various grain and base block combinations were studied, which included fairly regular shaped Leighton Buzzard sand (LBS) as a natural material and granite or rubber as base blocks, apart from the use of engineered materials for the grains (chrome steel balls, glass balls) and blocks (stainless steel, brass). The methodology used in this study to obtain the COR values for fairly regular shaped LBS grains can also be used for irregular shaped granular materials. Even though the size 
range (approximately $2 \mathrm{~mm}$ in diameter) tested in this study is narrow, this forms a good basis to analyse the behaviour of grains of greater size using numerical tools (i.e., DEM).

\section{Materials}

\subsection{Basic description of materials}

The impact behaviour of various grain types of the sphere configuration against base blocks of different material types was examined experimentally in this study (i.e. grain-block collision). The grains included commercially available chrome steel balls (CSB) and glass balls (GB) of $2 \pm 0.02 \mathrm{~mm}$ in diameter and regular shaped Leighton Buzzard sand (LBS) grains as a natural material. The LBS is a silica-rich sand with relatively smooth surfaces. The LBS grains used in this study were of $2 \pm 0.2 \mathrm{~mm}$ in diameter (average size in all three directions) which were measured by Vernier calliper with a resolution of $0.01 \mathrm{~mm}$. The LBS grains which had reasonably high sphericity (0.9) and roundness (0.8) were selected for the impact tests. Sphericity quantifies the degree to which particle approaches the shape of a sphere. Roundness is a measure of the sharpness of the edges and corners. Shape descriptors of sphericity and roundness were estimated based on visual observation of the grains and the use of an empirical chart proposed by Krumbein and Sloss (1963).

For natural sand grains with irregular surface roughness, internal defects and different morphologies, in the present study fairly regular shaped (high sphericity and high roundness) quartz sand grains were handpicked and tested while trying to reduce the effect of shape by handpicking regular grains. For irregular grains image analysis techniques can be used to

obtain the shape of the particle. However, the local radius of the sand grains at the point of contact with the block will affect the behaviour after impact and COR. With the present available techniques it is difficult to obtain the local radius of the grain at the point of contact. As the grains tested were regular in shape, the shape analysis is not presented in this study. 
The base blocks used in this study were brass, stainless steel, rubber and granite. The collision mechanism of grains impacting on the surfaces of granite and rubber blocks is helpful in various geotechnical and geological engineering applications, especially in the design of barriers for granular flows. In this preliminary study, quartz sand grains were tested as silica is the major constituent of weathered debris flow materials. During the debris flows the weathered materials slide on the surfaces of fresh material, therefore, the fresh granite base block was used. Apart from engineered and granite base blocks, the rubber block was also used to simulate the interactions between particles and flexible type barriers. The base blocks were of 9x9cm square and $6 \mathrm{~cm}$ thick. In Table 1, the grains and base blocks used in this study are summarized by providing some of their basic characteristics. The Poisson's ratio of the grains and blocks were obtained from literature sources based on the material type. The density of the spheres and blocks were measured in the laboratory. The density of the LBS grains is $2.65 \mathrm{t} / \mathrm{m}^{3}$, which was obtained from the water pycnometer method.

The chemical composition and surface morphological features of the tested grain and block materials were obtained through different techniques. The chemical composition of LBS grains was obtained through energy-dispersive X-ray spectroscopy (EDX) analysis. Silicon dioxide $\left(\mathrm{SiO}_{2}\right)$ was found to be the major constituent (around 80-90\%) with Iron and Aluminium oxides as minor constituents (around 5-10\% each). The Iron and Aluminium oxides present in LBS are majorly responsible for the orange colour of LBS grains. The surface roughness of the grains and the blocks was measured with an optical surface profiler (model: Veeco NT9300). The vertical scanning interferometry (VSI) mode was chosen, as this mode allows the scanning of large areas of materials in a non-destructive way to quantify roughness (Conroy and Mansfield, 2008). For both the grains and blocks, a field of view of $20 \times 20 \mu \mathrm{m}$ was selected for scanning to determine the roughness. The effect of curvature was 
removed for the grains and the roughness was presented as the root mean square (RMS) roughness denoted as $S_{q}$ based on Eq. (1) (as used by Senetakis et al., 2013).

$$
S_{q}=\sqrt{\frac{1}{a b} \sum_{i j} C_{i j}^{2}}
$$

where $\mathrm{a}$ and $\mathrm{b}$ are the number of points in the horizontal plane and $\mathrm{C}$ is the deviation of each point from the mean height value. Typical images of flattened three-dimensional surface profiles of an LBS grain and a rubber block are shown in Figure 1. For the different grain types, $\mathrm{S}_{\mathrm{q}}$ was measured by selecting randomly a total set of about ten grains from each brand. The effect of form on roughness was removed (flattened) for spheres and LBS grains by using a cylindrical function. For the blocks, surface roughness values were measured at ten different locations on the block surface which were chosen randomly. Compared to the engineered materials (chrome steel balls and glass balls), the LBS grains had greater value of surface roughness, which was expected to be observed for naturally occurring geological materials (Table 1).

\subsection{Determination of Young's modulus for the different material types}

Sandeep and Senetakis (2018) and Sandeep et al. (2018) determined the apparent values of Young's modulus of the CSB, GB and LBS grains in the laboratory. However, for the comprehensiveness of this study, the procedure is briefly presented in this section. The inter-

particle tests were conducted in the normal to the grain contacts direction using a micromechanical loading apparatus developed by Senetakis and Coop (2014). The grains were glued onto brass mounts and allowed to dry for a period of $24 \mathrm{hr}$. The top mount was fixed to the loading arm supported by a stainless steel frame, whereas the bottom mount was placed on a sled. During the application of the normal force, the top particle was moved downwards in a displacement-controlled mode till the target normal force was reached at the contact of the grains. 
Figure 2(a) shows a microscopic image of chrome steel balls during the application of the normal force. Representative curves of normal force against displacement along with Hertzian fitting (Hertz, 1882, after Johnson, 1985) are shown in Figure 2(b). This fitting is based on the following set of expressions presented in Eqs. (2) and (3) (Hertz, 1882, after Johnson, 1985):

$$
\begin{aligned}
& \alpha=\left(\frac{3 \mathrm{RF}_{\mathrm{N}}\left(1-v_{s}^{2}\right)}{4 \mathrm{E}_{s}}\right)^{\frac{1}{3}} \\
& \mathrm{~F}_{\mathrm{N}}=\frac{\sqrt{2}(\mathrm{R})^{\frac{1}{2}} \mathrm{E}_{s} \delta_{\mathrm{N}}^{\frac{3}{2}}}{3\left(1-v_{s}^{2}\right)}
\end{aligned}
$$

where $\mathrm{R}$ is the radius of the grains in contact taken as $\mathrm{R}=1 \mathrm{~mm}$ as the grains had a diameter of $2 \mathrm{~mm}, \alpha$ is the contact radius, $\mathrm{F}_{\mathrm{N}}$ and $\delta_{\mathrm{N}}$ are the normal force and displacement, $\mathrm{E}_{\mathrm{s}}$ and $v_{\mathrm{s}}$ are the contact Young's modulus and Poisson's ratio of the grains. The values of the Poisson's ratio from literature sources listed in Table 1 were used for the fitting. The value of contact Young's modulus is used as the fitting parameter to visually match the theoretical curve to the experimental curve. This value of Young's modulus is obtained by trial and error fitting to obtain the best fit by varying the value of $E_{s}$ presented in Eq. (3). For smooth surfaces, the contact Young's modulus can be similar with materials' Young's modulus. However, with the increase in roughness the contact Young's modulus is generally less than the materials' Young's modulus.

The average values of apparent Young's moduli of the grains are listed in Table 1 along with their standard deviations. The increasing order of Young's modulus of the grains is Leighton Buzzard sand (52GPa), glass balls (58GPa) and chrome steel balls (173GPa). For the base blocks, the values of Young's modulus were taken from literature sources ( $\mathrm{Gu}$ and Yang, 2013, Heyliger et al. 2003, Marinack et al. 2013, Gupta and Rao, 2000, Holownia, 1972). 
The contact behaviour between two bodies at the junction is governed by the Young's modulus and surface roughness of both bodies. The addition of moduli between the interacting bodies provides a way to use a single variable for different material combinations (Liu et al. 2005, Sandeep and Senetakis, 2019). The composite elastic Young's modulus (E*) for the grain and block combinations used in this study was obtained from Eq. (4) (after Johnson, 1985).

$$
\frac{1}{E^{*}}=\frac{1-v_{s}^{2}}{E_{s}}+\frac{1-v_{b}^{2}}{E_{b}}
$$

where $v_{\mathrm{s}}$ and $v_{\mathrm{b}}$ define the Poisson's ratio of the grain and block materials, and $E_{\mathrm{s}}$ and $\mathrm{E}_{\mathrm{b}}$ denote the elastic modulus of the grain and block, respectively. The composite surface roughness of the grain-block combinations in this study was obtained from Eq. (5) (after Johnson, 1985).

$$
\text { Composite }-S_{q}=\sqrt{S_{q g}^{2}+S_{q b}^{2}}
$$

where $\mathrm{S}_{\mathrm{qg}}$ and $\mathrm{S}_{\mathrm{qb}}$ are the RMS roughnesses of the grain and block, respectively.

\section{Experimental apparatus and testing programme}

\subsection{Micro-mechanical impact apparatus}

Researchers have found that the value of COR changes with the impact velocity (Thornton and Ning, 1998; Heibelmann et al., 2010, Brilliantov et al., 2007, Wong et al., 2009). It is important to use proper values of $\mathrm{COR}$ in the simulation of granular flows, as the energy transfer between the colliding particles governs the travel distance, the lateral spreading and the design of barriers (Paronuzzi, 1989, Davies and McSaveney, 1999). The impact experiments were conducted to determine the coefficient of restitution by using a custombuilt micro-mechanical impact apparatus which is shown in Figure 3(a). The apparatus 
consisted of various components including two solenoids, a base block, a cantilever pole, high speed cameras and focussed LED lights. The two solenoids were mounted on a steel frame (Figure 3(b)) and they were connected to the cantilever pole which is fixed rigidly to the base. The solenoids were of $20 \mathrm{~mm}$ in diameter and $39 \mathrm{~mm}$ in length with a holding force capacity of $13 \mathrm{~N}$ and they were used as the holding system of the grain which was dropped onto the base block. The cantilever pole was used to adjust the height of the drop. The apparatus can test particles ranging from about 1 to $3 \mathrm{~mm}$ in diameter and the drop heights can be adjusted up to about $500 \mathrm{~mm}$.

A schematic view of the apparatus is given in Figure 4, showing the initial drop height $h_{1}$, which was calculated from the centre of the solenoids system to the surface of the base block. The particle was initially held in position by the plungers of the solenoids before the drop. The plungers were of $7.7 \mathrm{~mm}$ in diameter and they were wrapped with a coil spring. The solenoids were controlled by an external switch which allowed the flow of electric current. As the electric current flowed into the solenoids, electro-magnetic energy was generated, which then pulled both the plungers backwards into the solenoids at the same time and the particle was released to drop onto the base block. This type of setup could minimize the initial spin during the drop. The whole experimental apparatus was placed into a Perspex chamber to minimize air flow effects. In most of the previously developed apparatus by other researchers, mainly spherical grains were impacted on blocks and the collision behaviour was analysed with the use of single high speed camera. The advantage of the newly developed apparatus compared with those from previous studies is the use of a simple solenoid system to hold the particles and the ability to track the path of the particle in the out of the plane direction as well to analyse the rebound height of the grain from both directions. This is particularly necessary for the LBS grains and other types of soil grains where the rebound path generally differs from the initial drop path. 


\subsection{Testing programme}

Twelve different grain-block combinations were tested in this study at four different drop heights of 155, 190, 240 and $300 \mathrm{~mm}$. Five trials were performed on CSB and GB grains and ten to twelve trials were performed on LBS particles at different drop heights for each grainblock combination. For the whole range of tests conducted using CSB and GB, a total of around 160 tests were performed and for the whole range of tests conducted using LBS grains, a total of around 190 tests were performed. The drop and rebound of the grain were captured by high speed cameras with a shutter speed of one thousand frames per second. The video was later used to analyse the grain initial drop and rebound paths. The high speed cameras were placed perpendicularly to each other to ensure the verticality of the rebounding path of the grains in the out of plane view, which was particularly important in the experiments with natural sand grains. LED lights were focussed on the travel path of the grain to increase the exposure time without compromising the frame rate. For a given grainblock combination, a new grain and a different position of the block were chosen for each new test. During the impact tests indentations were observed visually on the surface of the brass block after impact. However, for the experiments conducted in this testing programme, the blocks were always shifted/rotated in position to prevent the effect of plastic hardening. Since the grains were dropped from different heights, a study of the influence of impact velocity on the COR could also be conducted.

\section{Analytical expressions}

When two bodies impact each other, the velocities after the impact cannot be determined only by linear momentum equations as they undergo plastic deformations. The coefficient of restitution (COR) between two impacting bodies is given by Eq. (6). 


$$
C O R=\frac{V_{2 b}-V_{2 s}}{V_{1 s}-V_{1 b}}
$$

where, $V_{1 s}, V_{1 b}$ and $V_{2 s}, V_{2 b}$ are the velocities of the grain and block before and after impact, respectively.

In the present experimental program, as the base blocks are stationary, Eq. (6) is simplified to Eq. (7):

$$
C O R=\frac{-V_{2 s}}{V_{1 s}}
$$

There is a possibility of errors in calculating COR even with the minimum possible difference in the measurement of velocities based on particle tracking. Hence, in this study, the value of COR was calculated by using drop and rebound heights. If a grain is released from an initial height $h_{1}$ on a base block and it rebounds to height $h_{2}$, the impact and rebound velocities of the grain can be determined from kinematics as presented in Eqs. (8 and 9). For the drop heights of 155, 190, 240 and 300mm, the initial velocity of drop is calculated (Eq. 8) as 1.74, 1.93, 2.17 and $2.43 \mathrm{~m} / \mathrm{s}$, respectively.

$$
\begin{aligned}
& V_{1 s}=-\sqrt{2 g h_{1}} \\
& V_{2 s}=\sqrt{2 g h_{2}}
\end{aligned}
$$

where $\mathrm{g}$ is the acceleration due to gravity. Incorporating Eqs. (8) and (9) in Eq. (7), COR can be expressed as Eq. (10): 


$$
C O R=\sqrt{\frac{h_{2}}{h_{1}}}
$$

However, air drag can also affect the COR of the grain-block impact as the grains are dropped from rest. If the air drag is included in Eq. (10), it will produce Eq. (11).

$$
C O R=\left(\sqrt{\frac{g+\frac{F_{D 1}}{m_{s}}}{g-\frac{F_{D 2}}{m_{s}}}}\right)\left(\sqrt{\frac{h_{2}}{h_{1}}}\right)
$$

where $F_{D 1}$ and $F_{D 2}$ are the drag forces and $m_{s}$ is the mass of the sphere. Based on the drop heights and the grain sizes, the gravitational acceleration force is much greater than the acceleration due to air drag. Hence, the air drag terms $\left(\mathrm{F}_{\mathrm{D} 1} / \mathrm{m}_{\mathrm{s}}\right.$ and $\left.\mathrm{F}_{\mathrm{D} 2} / \mathrm{m}_{\mathrm{s}}\right)$ are neglected, and Eq. (11) will reduce back to Eq. (10). The analysis by Marinack et al. (2013) and Patil and Higgs (2017) of similar drop velocities showed that the air drag is negligible, and the COR values only differ less than $1 \%$ if air drag is considered. The impact of the grain on the block can vary from perfectly elastic to perfectly plastic. When the impact between grain and block is perfectly elastic, then the COR is equal to unity. However, for elastic-plastic impacts, the COR value varies between zero and one, and for perfectly plastic impacts, the COR value is zero. With reference to several experimental and theoretical works during impact, a substantial amount of kinetic energy is transformed as elastic waves propagate in the solid bodies (Stronge, 2000, Raman, 1920, Zener, 1941, Reed, 1985). The loss of energy ( $\Delta \mathrm{D})$ during the impact of grain on the block surface can be calculated from Eq. (12), and the energy loss percentage $(\% \Delta \mathrm{D})$ is give in Eq. (13).

$$
\begin{gathered}
\Delta D=m_{s} g\left(h_{1}-h_{2}\right)=m_{s} g h_{1}\left(1-C O R^{2}\right) \\
\% \Delta D=100\left(1-C O R^{2}\right)
\end{gathered}
$$




\section{Results and discussion}

In this work several experiments were conducted to determine the COR values of different grain types impacting different surfaces. The results of the current testing programme are listed in Table 2 and 3 showing average values of COR for CSB, GB and LBS grains impacting on various base blocks, respectively. All the tests were conducted under normal atmospheric pressure and room temperature $\left(23-24^{\circ} \mathrm{C}\right)$.

\subsection{Coefficient of restitution of engineered grains}

Figure 5 shows the various stages of impact of CSB on the surface of stainless steel block. The initial path of drop is shown in Figures 5(a and b), while the rebound path is presented in Figures 5 (c and d). It was observed that after the impact, the CSB grain rebounded following the exact same path. Figure 6 shows the repeatability in COR values of CSB impacting on stainless steel and granite blocks. Within the minimal scatter of the results, the COR values of CSB-stainless steel collisions decreased with the increase in impact velocity. However, no such trend was observed for CSB-granite collisions.

Figure 7 gives the COR values of CSB and GB impacting on brass and stainless steel base blocks at different velocities. In the legends of the Figures $(6,7,8,11$ and12), the grain-block combinations are specified with grain in the first position and base block in the second position. For example, in the legend of Figure 7, CSB-brass denotes the grain type to be chrome steel ball (CSB) and the base block to be brass.

It was observed from Figure 7 that the COR values of CSB impacting on metal blocks were lower compared to GB. For GB and CSB grains impacting on a stainless steel block, greater values of COR were observed compared to impacts on a brass block. For both GB and CSB, there was a steady and continuous drop of COR values with the increase in impact velocity. For different combinations, the decrease in COR values with change in velocity from 1.74 to 
$2.43 \mathrm{~m} / \mathrm{s}$ was equal to $5 \%, 6 \%, 6 \%$ and $10 \%$ for GB-brass, GB-stainless steel, CSB-brass and CSB-stainless steel, respectively. Previous works (Wong et al., 2009, Aryaei et al., 2010, Marinack et al., 2013, Patil and Higgs, 2017) also found that the COR values for metallic collisions decrease with the increase in impact velocity. In the present work, for CSB impacting on the surfaces of stainless steel, the average values of COR for different impact heights ranged from 0.63 to 0.69 . The present values of experimental COR for metallic collisions agree with the previous experimental work by Wong et al. (2009). For steel balls colliding with a steel block, Wong et al. (2009) reported values of COR ranging between 0.63 $(2.5 \mathrm{~m} / \mathrm{s})$ and $0.68(1.5 \mathrm{~m} / \mathrm{s})$ and that COR decreased with the increase in impact velocity.

Figure 8 shows the COR values against the impact velocity for CSB grains impacting on different surfaces. From Figure 8 it was observed that the lower and higher values of COR were found for CSB impacting on rubber block (average COR=0.42) and granite block (average $\mathrm{COR}=0.90$ ). Similar results could be observed when the glass balls impacted on rubber block (average $\mathrm{COR}=0.37$ ) and granite block (average $\mathrm{COR}=0.94$ ) (Table 2). Nonetheless, the impact of GB on various block combinations had higher value of COR when compared with CSB. For GB and CSB impacting on the surfaces of granite and rubber base blocks with varying the impact velocities, no significant changes were observed in the COR values. For the GB and CSB combinations the scatter in the COR values was very small in magnitude, for example, for CSB-stainless steel impacts (velocity $=1.74 \mathrm{~m} / \mathrm{s}$ ) the minimum and maximum values of COR were equal to 0.68 and 0.72 , respectively. Similarly, for GBstainless steel impacts (velocity $=1.74 \mathrm{~m} / \mathrm{s}$ ), the minimum and maximum values of COR were equal to 0.85 and 0.87 , respectively. The values of standard deviations were not specified separately for grain-block combinations of CSB and GB impacts as they are based on five trials only. Thereby the values of standard deviations are not totally reliable. However, the minimum and maximum values of standard deviation in COR values for GB and CSB 
impacts on all base block combinations are 0.003 and 0.012 , respectively. This small scatter in COR values is generally expected for engineered grains as they are spherical in shape with consistent morphological and elastic characteristics.

\subsection{Coefficient of restitution of natural soil grains}

Figure 9 shows the various stages of an LBS grain impacting on the surface of brass block. Figure 9 ( $a$ and $b$ ) shows the path of the particle after release and Figure 9 (c and d) shows the position of the particle after rebounding. Unlike CSB and GB, where the grains after impact rebound following the exact same paths as that during the initial drop travel path, some of the LBS particles deviated slightly from the initial drop path after rebounding as shown in Figure 9 (c and d). For the sand particles deviating from the initial path of drop, the rebound height ' $\mathrm{h}_{2}$ ' is calculated based on the resultant change in the horizontal and vertical distances (as used by Banks et al., 2005). For LBS grain impacts, the rebounding path was checked from the out-of-plane direction as well. Experiments which showed deviations in the out-of-plane view were excluded from the data analysis.

Figure 10 shows a schematic representation of an LBS grain after impact, which is deviating from the initial drop path. Even though regular shaped LBS grains were tested in this study, the deviation from the path of drop after rebound was due to natural variabilities, internal flaws and small irregularities in the shape of the LBS grains compared with a perfectly spherical shape without any irregularities of CSB and GB grains. This is a major difference in the collision behaviour between natural LBS grains and engineered grains like GB and CSB. Even though in this study the tests are conducted on fairly regular shaped LBS grains, similar methodology to measure the resultant rebound height can be used to obtain the values of COR for irregular shaped LBS grains and other granular materials as well.

Figure 11 shows the average COR values of LBS grains when impacted on different base blocks at different velocities. The average values of COR along with their standard deviations 
for different combinations with LBS grains are presented in Table 3. For the velocities used in this testing programme, the average values of COR of LBS impacting on surfaces of brass, stainless steel, granite and rubber blocks were equal to $0.56,0.68,0.79$ and 0.43 , respectively. The spectrum of COR values of LBS grains impacting on stainless steel surfaces lies in the same range of values obtained by $\mathrm{Yu}$ and Tafti (2016) for quartz sand grains at similar velocities. Similar to $\mathrm{CSB}$ and GB, the COR values of LBS were higher and lower when they were impacting on surfaces of granite and rubber blocks, respectively. Among LBS particles impacting on metal surfaces, higher values of COR were observed when impacting on the surfaces of stainless steel compared with brass. From Table 3, a greater degree of scatter was observed for LBS grains compared to impacts of CSB and GB. The values of standard deviation observed for LBS grains were approximately one order of magnitude greater than the CSB and GB impacts. The minimum and maximum values of standard deviations in COR values for LBS grain impacts are 0.020 and 0.080 respectively. Correspondingly, the minimum and maximum values of COR for LBS-stainless steel block impacts were equal to 0.52 and 0.78 , respectively. Similar degree of scatter in COR values was observed for all the test combinations with LBS grains.

\subsection{Coefficient of restitution and energy loss}

Figure 12 shows the COR values for all the grain types against different base block impacts. From Figure 12 it is observed that, for all the combinations, the COR values can be segregated into three categories based on the base blocks used. The higher and lower values of COR were found for granite block (0.75-0.95) and rubber (0.37-0.44) combinations, respectively. The values of COR between GB and granite block were the greatest in magnitude among all the test combinations used. These observations might be due to the brittle nature of glass and granite which results in very small to negligible plastic 
deformations of asperities during the impact, reaching in this way greater rebound heights after impact by retaining large part of the initial kinetic energy. Marinack et al. (2013) testing the impact behaviour of glass balls, observed similar high values of COR and they attributed this behaviour to the brittle nature of glass. For the brass and stainless steel blocks visible plastic deformations were observed on the surface after impact. However, for the granite blocks no visible changes were observed on the surface after impact. The maximum area that can be scanned with the optical surface profiler is approximately $200 \mu \mathrm{m}^{2}$. Without any observable changes it is difficult to obtain the exact contact location of the impact on the surface of the block or the grains used. Therefore the surface roughness was not measured after impact.

Figures 13 and 14 show the variation of the average COR values with composite Young's modulus and composite surface roughness, respectively. The values of composite Young's modulus and composite surface roughness are calculated from Eqs. (4) and (5). From Figure 13, for low values of composite Young's modulus (around 0.1GPa for impacts on the rubber block) the average values of COR were relatively low in magnitude. The lower values of COR for impacts on the rubber block are possibly due to the dissipation of energy because of the greater contact area; this greater contact area is related to the low composite Young's modulus (Hertz, 1882) of the grain-rubber block interface. As highlighted earlier, in static normal loading tests from recent studies, the effect of surface roughness was quantified on the contact behaviour of grains (Sandeep and Senetakis, 2018, Nardelli and Coop, 2018). However, for the narrow range of composite surface roughness of the grain-block interfaces in the present study no particular trend was observed in the COR values (Figure 14). Hence, from Figures 13 and 14 for the tested grain-block combinations, it is concluded that the COR values did not show specific trends within the narrow range of variation of the composite 
surface roughness, yet, low values of COR were observed for impacts with lower values of composite Young's modulus.

The average values of percentage of energy loss $(\% \Delta \mathrm{D})$ for all the grains impacting on block at the tested velocities are illustrated in the form of histograms in Figure 15. From Figure 15, it was observed that for all the grain-block combinations, the energy loss was maximum when rubber block was used as the base material. The grains after impacting the rubber block lost at least $80 \%$ of the initial kinetic energy due to greater contact area, probably in the form of heat due to elastic hysteresis.

In the cases of grains impacting on the surface of brass block the energy loss was greater compared with collisions on stainless steel block. The lower values of Young's modulus of brass (100GPa) helps in generating greater contact area during impact compared to stainless steel which might have caused the reduction in COR values. However, compared with GB, the metallic collisions of CSB with brass and stainless steel block had lower values of COR (E* values are lower for GB compared to $\mathrm{CSB}$ ). This is probably due to the plastic deformations caused during impact which resulted in the dissipation of kinetic energy. Throughout the total set of experiments, the combinations with brittle material (granite) had greater values of COR and less energy loss, which is due to the brittle nature of impacts and because the grains retained large part of the initial kinetic energy. From Table 3 and Figure 15, the increasing order of energy loss for LBS grains impacting on various surfaces are granite $(37 \%)$, stainless steel (53\%), brass $(69 \%)$ and rubber (82\%). Compared with GB and CSB, greater degree of scatter in the COR values was observed for fairly regular shaped LBS grains as individual grains can vary in elastic and morphological characteristics (Penumadu et al., 2009, Yu and Tafti, 2016). Additionally, the surface roughness and minor irregularities in shape may also have contributed to these higher deviations observed. Wang et al. (2016) for corn grains, showed experimentally that the COR is affected by the grain shape and also it 
varies from position to position on the same grain, i.e. higher values of COR for round shaped grains are observed compared with wedge shaped grains.

It is acknowledged that in the present study only engineered grains of perfect spherical shape and natural grains of fairly regular shape were tested by impacting on blocks of variable types, while in a real debris flow grains/fragments may have shape which deviates that of the sphere with high angularity. Morphology of grains in terms of sphericity and roundness is expected to have an influence on the COR values which worth further investigation in future studies. The current study can be used as a reference to study the COR values of real debris flow materials and also for the calibration of DEM models.

\section{Conclusions}

In this work, the impact between various grain and base block types was investigated in terms of the coefficient of restitution (COR) and energy loss percentage using a newly developed custom-built micro-mechanical impact apparatus. The repeatability of the new micromechanical impact apparatus was verified by impacting chrome steel balls on stainless steel block. An inter-particle loading apparatus, previously presented by the authors, was used to determine the apparent Young's moduli of the grains, while the Young's moduli of the blocks were extracted from literature sources.

Based on the experimental results, it was found that the COR of glass balls was higher compared with steel balls, as the metallic steel balls experience loss of energy due to plastic deformations. The average value of COR of fairly regular shaped LBS grains impacting on surfaces of brass, stainless steel, granite and rubber blocks was found to be $0.56,0.68,0.79$ and 0.43 , respectively. Compared to engineered grains, fairly regular shaped LBS, which is a natural quartz sand, had greater degree of scatter in the COR values, which is, mostly because 
of the varying elastic and morphological characteristics among different natural grains of LBS and their relatively irregular shape when compared with the perfect spherical shape of glass and chrome steel balls. In all the test combinations, the grains impacting on granite surface showed higher values of the COR (0.75-0.95) due to the brittle nature of granite and thereby grains retained most of their kinetic energy post collision. The impacts on rubber blocks were found to result in lower values of COR $(0.37-0.44)$ due to the low stiffness of rubber and the significant amount of energy dissipated as heat. Within the narrow range of composite surface roughness of the grain-block interfaces used in this study, no effect was observed in the average COR values. However, impacts between materials with low composite Young's modulus showed lower values of average COR, particularly when rubber was used as base block. The results of the study can provide useful input parameters, in terms of the coefficient of restitution, in discrete numerical analyses of debris flow problems and can help researchers to simulate different barrier types in studies focusing on the impact behaviour of debris flows.

Acknowledgments: The authors appreciate the constructive comments and suggestions made by the reviewers to improve the quality of the manuscript. The authors acknowledge the grants from the Research Grants Council of the Hong Kong Special Administrative Region, China, project no. T22-603/15 N (CityU 8779012)) and project no. 9042491 (CityU 11206617). 


\section{References}

Agliardi, F., \& Crosta, G. B. (2003). High resolution three-dimensional numerical modelling of rockfalls. International Journal of Rock Mechanics and Mining Sciences, 40(4), 455471.

Aryaei, A., Hashemnia, K., Jafarpur, K. (2010). Experimental and numerical study of ball size effect on restitution coefficient in low velocity impacts. International Journal of Impact Engineering, 37(10), 1037-1044.

Asteriou, P., Saroglou, H., \& Tsiambaos, G. (2012). Geotechnical and kinematic parameters affecting the coefficients of restitution for rock fall analysis. International Journal of Rock Mechanics and Mining Sciences, 54, 103-113.

Banks, M., Bridges, N. T., \& Benzit, M. (2005). Measurements of the coefficient of restitution of quartz sand on basalt: implications for abrasion rates on Earth and Mars. In proc. Lunar and planetary science XXXVI.

Brilliantov, N. V., Albers, N., Spahn, F., \& Pöschel, T. (2007). Collision dynamics of granular particles with adhesion. Physical Review E, 76(5), 051302.

Calvetti, F., \& Nova, R. (2004). Micromechanical approach to slope stability analysis. In Degradations and instabilities in geomaterials (pp. 235-254). Springer, Vienna.

Cascante, G., \& Santamarina, J. C. (1996). Interparticle contact behaviour and wave propagation. Journal of Geotechnical Engineering, 122(10), 831-839.

Cavarretta, I., Rocchi, I., Coop, M.R., (2011). A new interparticle friction apparatus for granular materials. Can. Geotech. J. 48 (12), 1829-1840.

Chen, H., \& Lee, C. F. (2000). Numerical simulation of debris flows. Canadian Geotechnical Journal, 37(1), 146-160.

Cheung, L. Y. G., O’Sullivan, C., \& Coop, M. R. (2013). Discrete element method simulations of analogue reservoir sandstones. International journal of rock mechanics and mining sciences, 63, 93-103.

Choi, C. E., Ng, C. W. W., Law, R. P., Song, D., Kwan, J. S. H., \& Ho, K. K. S. (2014). Computational investigation of baffle configuration on impedance of channelized debris flow. Canadian Geotechnical Journal, 52(2), 182-197.

Clelland, R., \& Hrenya, C. M. (2002). Simulations of a binary-sized mixture of inelastic grains in rapid shear flow. Physical Review E, 65(3), 031301.

Coetzee, C. J. (2017). Calibration of the discrete element method. Powder Technology, 310, 104-142. 
Cole, D.M., Mathisen, L.U.; Hopkins, M.A.; Knapp, B.R. (2010). Normal and sliding contact experiments on gneiss. Granul. Matter, 12, 69-86.

Conroy, M., \& Mansfield, D. (2008). Scanning interferometry: Measuring microscale devices. Nature Photonics, 2(11), 661.

Cundall, P. A., Strack, O. D. (1979). A discrete numerical model for granular assemblies. Geotechnique, 29(1), 47-65.

Dahl, S. R., Clelland, R., \& Hrenya, C. M. (2003). Three-dimensional, rapid shear flow of particles with continuous size distributions. Powder technology, 138(1), 7-12.

Davies, T. R., \& McSaveney, M. J. (1999). Runout of dry granular avalanches. Canadian Geotechnical Journal, 36(2), 313-320.

Descoeudres, F., \& Zimmermann, T. H. (1987). Three-dimensional dynamic calculation of rockfalls. In 6th ISRM Congress. International Society for Rock Mechanics.

Di Prisco, C., \& Vecchiotti, M. (2006). A rheological model for the description of boulder impacts on granular strata. Geotechnique, 56(7), 469.

Dufek, J., Manga, M., \& Patel, A. (2012). Granular disruption during explosive volcanic eruptions. Nature Geoscience, 5(8), 561.

Durda, D. D., Movshovitz, N., Richardson, D. C., Asphaug, E., Morgan, A., Rawlings, A. R., \& Vest, C. (2011). Experimental determination of the coefficient of restitution for meter-scale granite spheres. Icarus, 211(1), 849-855.

Foerster, S. F., Louge, M. Y., Chang, H., \& Allia, K. (1994). Measurements of the collision properties of small spheres. Physics of Fluids, 6(3), 1108-1115.

Garcia, M. C., Feise, H. J., Strege, S., \& Kwade, A. (2016). Segregation in heaps and silos: Comparison between experiment, simulation and continuum model. Powder Technology, 293, 26-36.

Gischig, V. S., Hungr, O., Mitchell, A., \& Bourrier, F. (2015). Pierre3D: a 3D stochastic rockfall simulator based on random ground roughness and hyperbolic restitution factors. Canadian Geotechnical Journal, 52(9), 1360-1373.

Greenwood, J. A., \& Tripp, J. H. (1967). The elastic contact of rough spheres. Journal of Applied Mechanics, 34(1), 153-159.

Gu, X. Q., \& Yang, J. (2013). A discrete element analysis of elastic properties of granular materials. Granular Matter, 15(2), 139-147.

Gupta, A. S., \& Rao, K. S. (2000). Weathering effects on the strength and deformational behaviour of crystalline rocks under uniaxial compression state. Engineering Geology, 56(3-4), 257-274. 
Heibelmann, D., Blum, J., Fraser, H. J., \& Wolling, K. (2010). Microgravity experiments on the collisional behaviour of saturnian ring particles. Icarus, 206(2), 424-430.

Hertz, H., (1882). Uber die Beruhrang fester elastischer Korper (On the contact of elastic solids), Journal für die reine und angewandte Mathematik, 92, 156-171.

Heyliger, P., Ledbetter, H., \& Kim, S. (2003). Elastic constants of natural quartz. The Journal of the Acoustical Society of America, 114(2), 644-650.

Holownia, B. P. (1972). Effect of Poisson's ratio on bonded rubber plateblocks. Journal of Strain Analysis, 7(3), 236-242.

Imre, B., Räbsamen, S., \& Springman, S. M. (2008). A coefficient of restitution of rock materials. Computers \& Geosciences, 34(4), 339-350.

Iverson, R. M. (1997). The physics of debris flows. Reviews of geophysics, 35(3), 245-296.

Jasti, V. K., \& Higgs, C. F. (2010). A fast first order model of a rough annular shear cell using cellular automata. Granular Matter, 12(1), 97-106.

Jiang, S., Shen, L., Guillard, F., \& Einav, I. (2018). Energy dissipation from two-glass-bead chains under impact. International Journal of Impact Engineering.

Johnson, K. L. (1985). Contact Mechanics. Cambridge University, New York.

Karolyi, A., \& Kertesz, J. (1998). Lattice-gas model of avalanches in a granular pile. Physical Review E, 57(1), 852.

Kharaz, A. H., \& Gorham, D. A. (2000). A study of the restitution coefficient in elasticplastic impact. Philosophical Magazine Letters, 80(8), 549-559.

Koller, M. G., \& Kolsky, H. (1987). Waves produced by the elastic impact of spheres on thick plateblocks. International journal of solids and structures, 23(10), 1387-1400.

Kozicki, J., \& Tejchman, J. (2005). Application of a cellular automaton to simulations of granular flow in silos. Granular Matter, 7(1), 45-54.

Krumbein, W. C., \& Sloss, L. L. (1963). Stratigraphy and sedimentation (No. QE571 K7 1963).

Li, X., \& Zhao, J. (2018). A unified CFD-DEM approach for modelling of debris flow impacts on flexible barriers. International Journal for Numerical and Analytical Methods in Geomechanics. https://doi.org/10.1002/nag.2806

Liu, S. B., Peyronnel, A., Wang, Q. J., \& Keer, L. M. (2005). An extension of the Hertz theory for three-dimensional coated bodies. Tribology Letters, 18(3), 303-314.

Lo, D. O. K. (2000). Review of natural terrain landslide debris-resisting barrier design. Geotechnical Engineering Office, Civil Engineering Department, Hong Kong. 
Lorenz, A., Tuozzolo, C., \& Louge, M. Y. (1997). Measurements of impact properties of small, nearly spherical particles. Experimental Mechanics, 37(3), 292-298.

Makris, N, Roussos, Y. S. (2000). Rocking response of rigid plateblocks under near-source ground motions. Geotechnique, 50(3), 243-262.

Marinack Jr, M. C., Musgrave, R. E., \& Higgs III, C. F. (2013). Experimental investigations on the coefficient of restitution of single particles. Tribology Transactions, 56(4), 572580.

Mitchell, A., \& Hungr, O. (2016). Theory and calibration of the Pierre 2 stochastic rock fall dynamics simulation program. Canadian Geotechnical Journal, 54(1), 18-30.

Nardelli, V., \& Coop, M. R. (2018). The experimental contact behaviour of natural sands: normal and tangential loading. Géotechnique. https://doi.org/10.1680/jgeot.17.P.167

Okura, Y., Kitahara, H., \& Sammori, T. (2000). Fluidization in dry landslides. Engineering Geology, 56(3-4), 347-360.

Paronuzzi, P. (1989). Probabilistic approach for design optimization of rockfall protective barriers. Quarterly Journal of Engineering Geology and Hydrogeology, 22(3), 175-183.

Patil, D., \& Higgs, C. F. (2017). A coefficient of restitution model for sphere-plateblock elastoplastic impact with flexural vibrations. Nonlinear Dynamics, 88(3), 1817-1832.

Penumadu, D., Dutta, A. K., Luo, X., \& Thomas, K. G. (2009). Nano and neutron science applications for geomechanics. KSCE Journal of Civil Engineering, 13(4), 233-242.

Pfeiffer, T. J., \& Bowen, T. D. (1989). Computer simulation of rockfalls. Bulletin of the association of Engineering Geologists, 26(1), 135-146.

Pun, W.K., Li, A.C.O., Cheung, L.L.K. \& Lam, H.W.K. (2011). Improvement to Geotechnical Practice Arising from Landslide Investigation. Proc. 14th Asian Regional Conference on Soil Mechanics and Geotechnical Engineering, Hong Kong, pp 188.

Raman, C. V. (1920). On some applications of Hertz's theory of impact. Physical Review, 15(4), 277.

Reed, J. (1985). Energy losses due to elastic wave propagation during an elastic impact. Journal of Physics D: Applied Physics, 18(12), 2329.

Ritchie, A. M. (1963). Evaluation of rockfall and its control. Highway research record, (17).

Sandeep, C. S., \& Senetakis, K. (2018). Effect of Young's Modulus and Surface Roughness on the Inter-Particle Friction of Granular Materials. Materials, 11(2), 217.

Sandeep, C. S., \& Senetakis, K. (2019). An experimental investigation of the microslip displacement of geological materials. Computers and Geotechnics, 107, 55-67. 
Sandeep, C. S., He, H., \& Senetakis, K. (2018). An experimental micromechanical study of sand grain contacts behavior from different geological environments. Engineering Geology. doi:10.1016/j.enggeo.2018.09.030

Sanvitale, N., \& Bowman, E. T. (2016). Visualization of dominant stress-transfer mechanisms in experimental debris flows of different particle-size distribution. Canadian Geotechnical Journal, 54(2), 258-269.

Senetakis K., Coop M R. (2014). The development of a new micro-mechanical inter-particle loading apparatus. Geotechnical Testing Journal, 37(6), 1028-1039.

Senetakis, K., Coop, M. R., \& Todisco, M. C. (2013). Tangential load-deflection behaviour at the contacts of soil particles. Géotechnique Letters, 3(2), 59-66.

Sondergaard, R., Chaney, K., \& Brennen, C. E. (1990). Measurements of solid spheres bouncing off flat plateblocks. Journal of Applied Mechanics, 112(3), 694-699.

Stronge, W. J. (2000). Impact mechanics. Cambridge university press.

Tabor, D. (1948). A simple theory of static and dynamic hardness. Proc. R. Soc. Lond. A, 192(1029), 247-274.

Thornton, C., \& Ning, Z. (1998). A theoretical model for the stick/bounce behaviour of adhesive, elastic-plastic spheres. Powder technology, 99(2), 154-162.

Turmel, D., \& Locat, J. (2010). Numerical modelling of underwater rockfalls. Canadian Geotechnical Journal, 48(1), 16-25.

Vincent, J. H. (1900). Experiments on impact. In Proc. Cambridge Philos. Soc (Vol. 8, pp. 332-357).

Wang, Z., Jacobs, F., \& Ziegler, M. (2016). Experimental and DEM investigation of geogridsoil interaction under pullout loads. Geotextiles and Geomembranes, 44(3), 230-246.

Wong, C. X., Daniel, M. C., \& Rongong, J. A. (2009). Energy dissipation prediction of particle dampers. Journal of Sound and Vibration, 319(1-2), 91-118.

Yang, L., Wang, D., Guo, Y., Liu, S. (2016). Tribological behaviours of quartz sand particles for hydraulic fracturing. Tribology International, 102, 485-496.

Yu, K., \& Tafti, D. (2016). Impact model for micrometer-sized sand particles. Powder Technology, 294, 11-21.

Zener, C. (1941). The intrinsic inelasticity of large plateblocks. Physical Review, 59(8), 669. 
Table 1. Material properties of the grains and blocks used in the experiments

\begin{tabular}{|c|c|c|c|c|c|}
\hline \multirow{2}{*}{ Type } & Material & $\begin{array}{c}\text { Poisson's } \\
\text { ratio }\end{array}$ & Density $\left(\mathrm{t} / \mathrm{m}^{3}\right)$ & Roughness(nm) & E (GPa) \\
\hline \multirow{4}{*}{ Grain } & Glass ball & $0.30^{\#}$ & 2.60 & $95 \pm 28$ & $58 \pm 7^{*}$ \\
\cline { 2 - 6 } & Chrome steel ball & $0.30^{\beta}$ & 7.70 & $62 \pm 19$ & $173 \pm 11^{*}$ \\
\cline { 2 - 6 } & Leighton Buzzard sand & $0.10^{\alpha}$ & 2.65 & $223 \pm 61$ & $52 \pm 12^{*}$ \\
\hline \multirow{4}{*}{ Block } & Brass & $0.35^{\beta}$ & 8.50 & $392 \pm 67$ & $100^{\beta}$ \\
\cline { 2 - 6 } & Stainless steel & $0.30^{\beta}$ & 7.80 & $310 \pm 54$ & $200^{\beta}$ \\
\cline { 2 - 6 } & Granite & $0.30^{\Lambda}$ & 3.00 & $412 \pm 35$ & 86 \\
\cline { 2 - 6 } & Rubber & $0.50^{\psi}$ & 1.50 & $270 \pm 42$ & 0.1 \\
\hline
\end{tabular}

*From inter-particle normal loading tests after Sandeep and Senetakis (2018), Sandeep et al. (2018)

${ }^{\#} \mathrm{Gu}$ and Yang, 2013, ${ }^{\alpha}$ Heyliger et al. 2003, ${ }^{\beta}$ Marinack et al. 2013, ${ }^{\wedge}$ Gupta and Rao, 2000, ${ }^{\psi}$ Holownia, 1972.

Table 2. Average values of the coefficient of restitution for chrome steel balls and glass balls with various block combinations at different impact heights and respective velocities

\begin{tabular}{|c|c|c|c|c|c|}
\hline \multirow{2}{*}{ Grain } & \multirow{2}{*}{ Block } & \multicolumn{4}{|c|}{ Coefficient of Restitution values } \\
\cline { 3 - 6 } & & $\mathrm{h}_{1}(\mathrm{~mm}): 155$ & 190 & 240 & 300 \\
\cline { 3 - 6 } & & Vel $(\mathrm{m} / \mathrm{s}): 1.74$ & 1.93 & 2.17 & 2.43 \\
\hline GB & Brass & 0.74 & 0.74 & 0.72 & 0.70 \\
\hline GB & Stainless steel & 0.86 & 0.86 & 0.83 & 0.81 \\
\hline GB & Granite & 0.93 & 0.95 & 0.95 & 0.92 \\
\hline GB & Rubber & 0.38 & 0.37 & 0.37 & 0.37 \\
\hline CSB & Brass & 0.54 & 0.53 & 0.52 & 0.51 \\
\hline CSB & Stainless steel & 0.69 & 0.66 & 0.65 & 0.63 \\
\hline CSB & Granite & 0.89 & 0.92 & 0.90 & 0.89 \\
\hline CSB & Rubber & 0.43 & 0.42 & 0.42 & 0.42 \\
\hline
\end{tabular}


Table 3. Average values of the coefficient of restitution for Leighton Buzzard sand with various block combinations at different impact heights and respective velocities

\begin{tabular}{|c|c|c|c|c|c|}
\hline \multirow{2}{*}{ Sphere } & \multirow{3}{*}{ Plate } & \multicolumn{4}{|c|}{ Coefficient of Restitution values } \\
\cline { 3 - 6 } & & $\mathrm{h}_{1}(\mathrm{~mm}): 155$ & 190 & 240 & 300 \\
\cline { 3 - 6 } & Vel $(\mathrm{m} / \mathrm{s}): 1.74$ & 1.93 & 2.17 & 2.43 \\
\hline LBS & Brass & $0.54 \pm 0.050$ & $0.55 \pm 0.040$ & $0.55 \pm 0.030$ & $0.58 \pm 0.030$ \\
\hline LBS & Stainless steel & $0.67 \pm 0.080$ & $0.68 \pm 0.060$ & $0.68 \pm 0.050$ & $0.70 \pm 0.030$ \\
\hline LBS & Granite & $0.75 \pm 0.080$ & $0.80 \pm 0.060$ & $0.80 \pm 0.070$ & $0.82 \pm 0.060$ \\
\hline LBS & Rubber & $0.44 \pm 0.030$ & $0.44 \pm 0.040$ & $0.43 \pm 0.020$ & $0.40 \pm 0.030$ \\
\hline
\end{tabular}




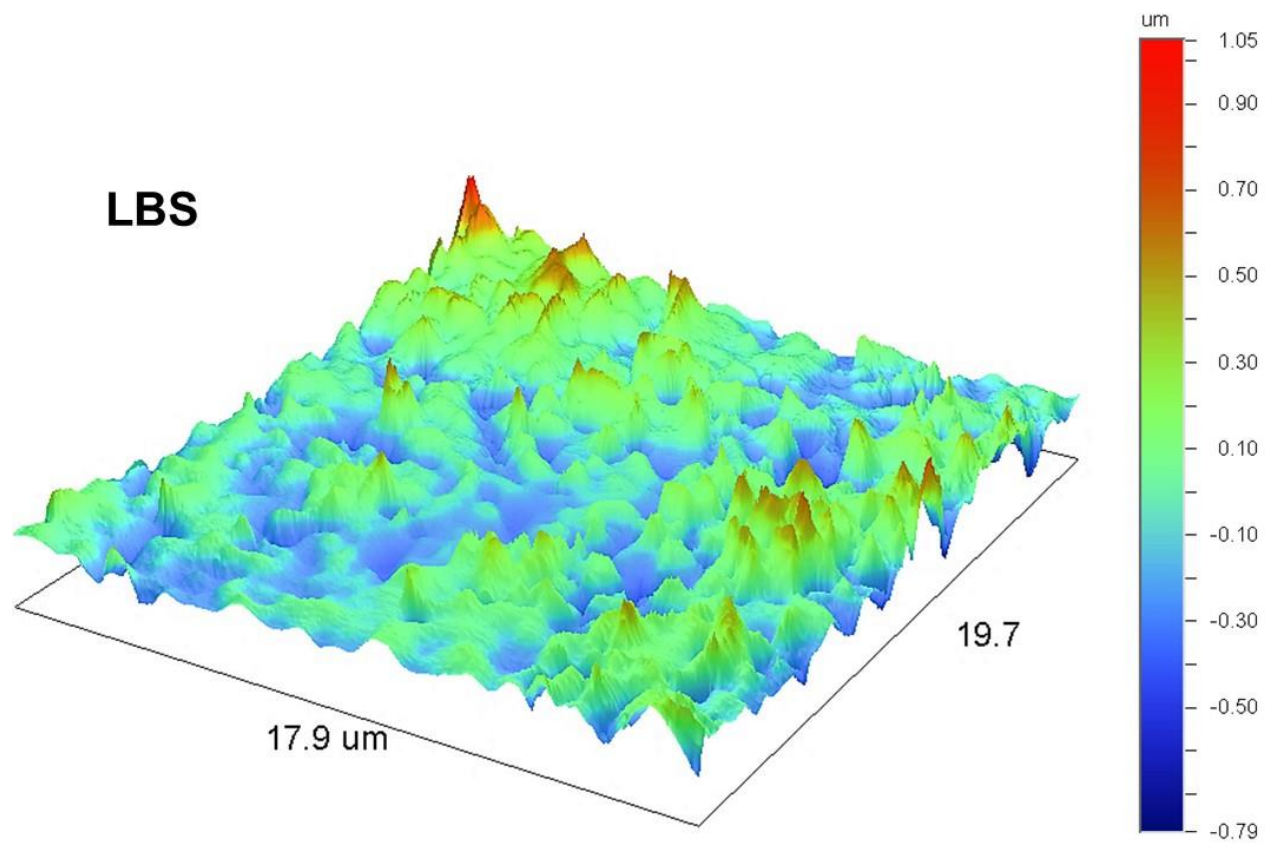

3

\section{Rubber plate}

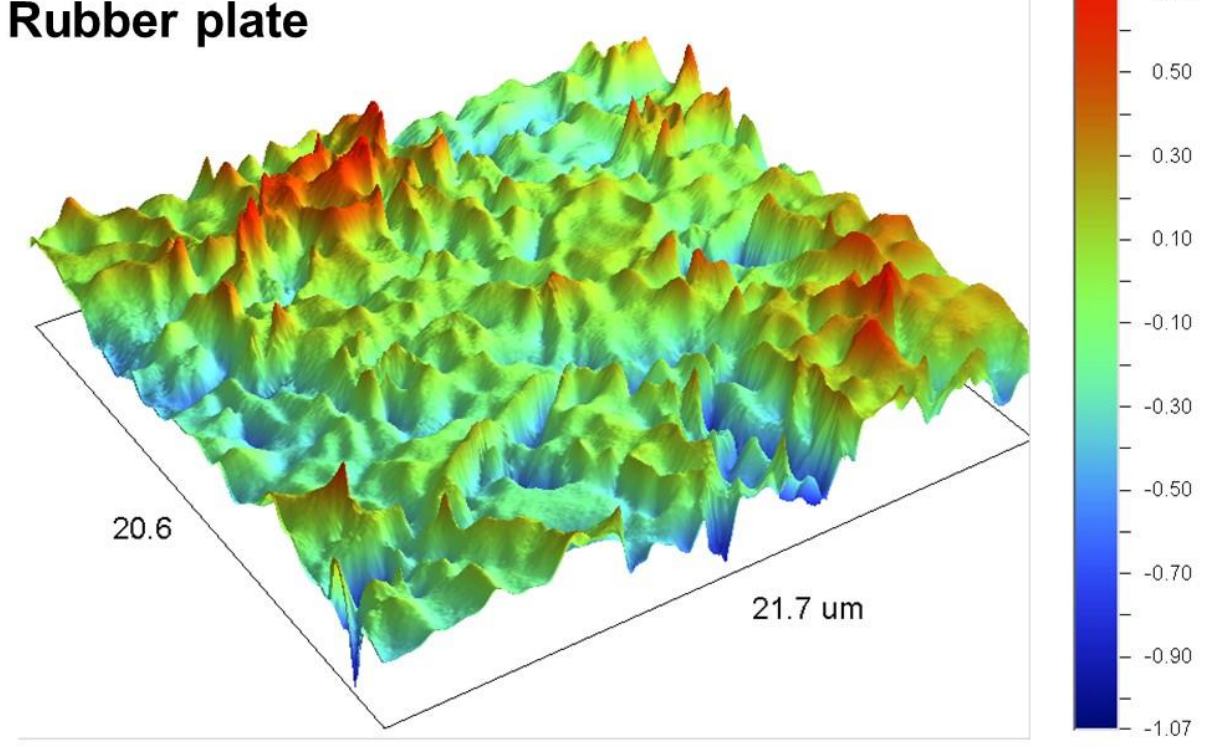

5

6 Figure 1. Flattened three-dimensional surface profiles of an LBS grain and a rubber block 7 
(a)
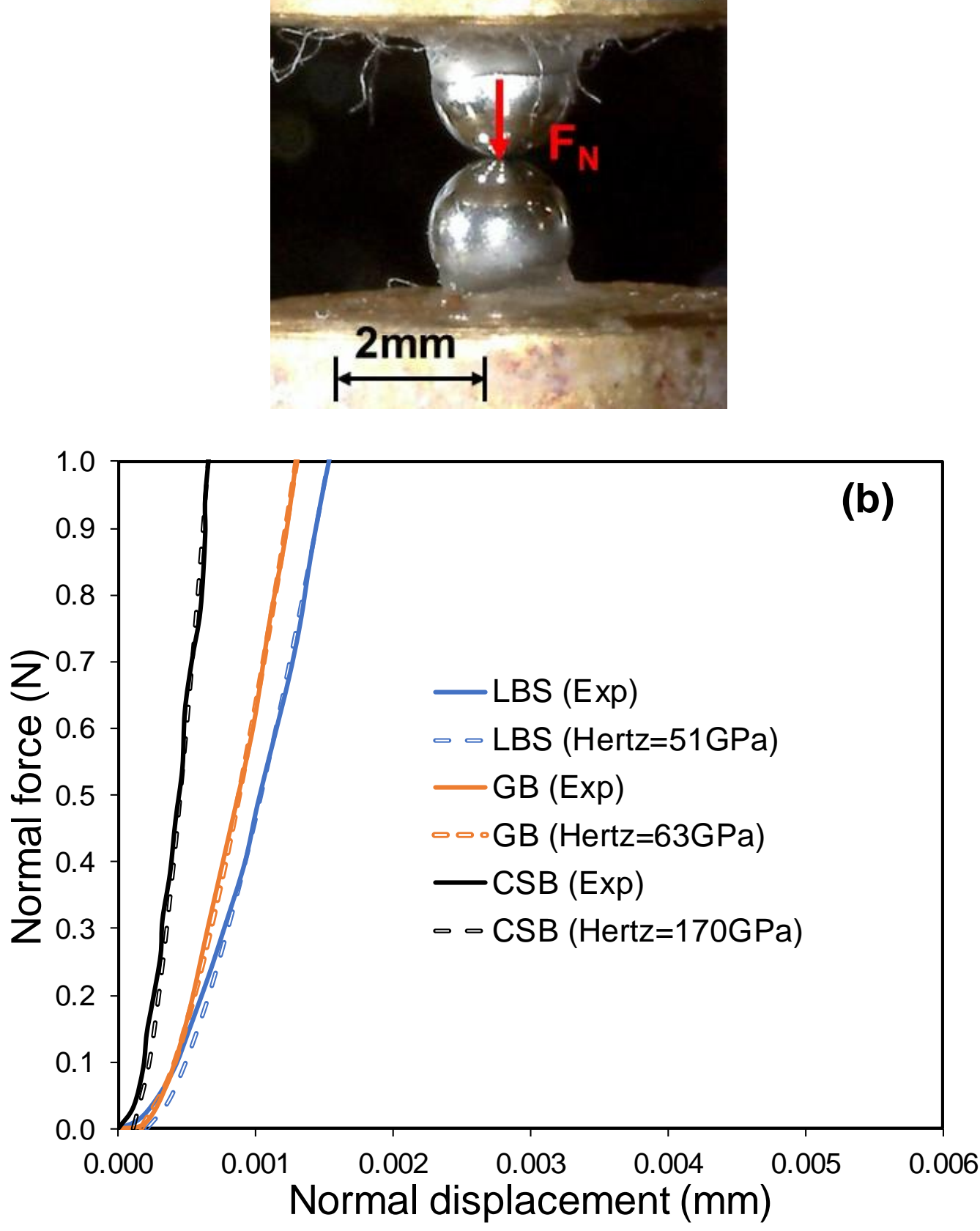

Figure 2. (a) Photograph of chrome steel balls during application of normal force using interparticle loading apparatus (b) The typical normal force against displacement behaviour along with Hertzian fitting for the spheres tested in this programme 

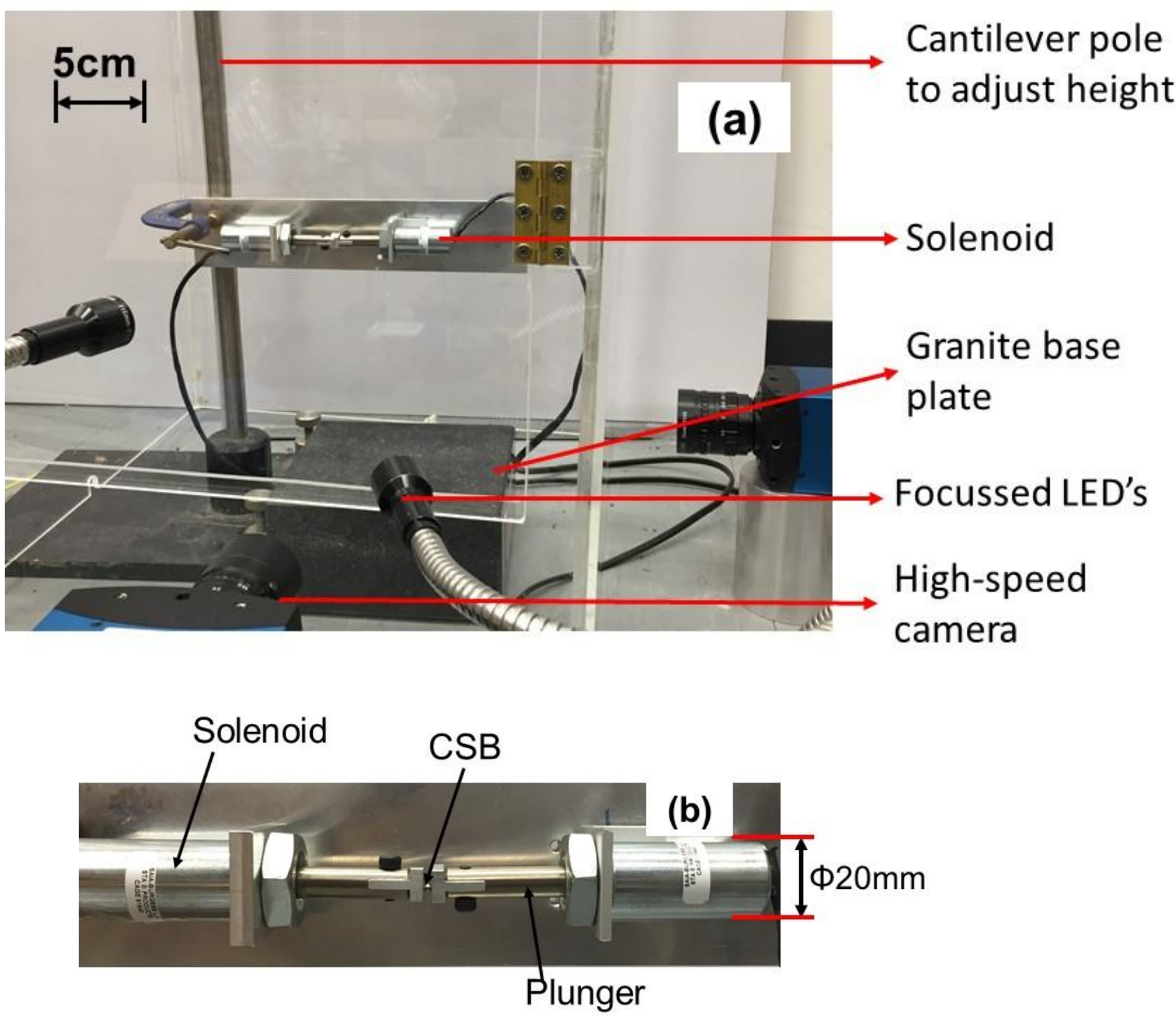

Figure 3. (a) Photograph of micro-mechanical impact apparatus inside a Perspex chamber showing major components (b) Photograph of Solenoids holding chrome steel ball before the drop test 


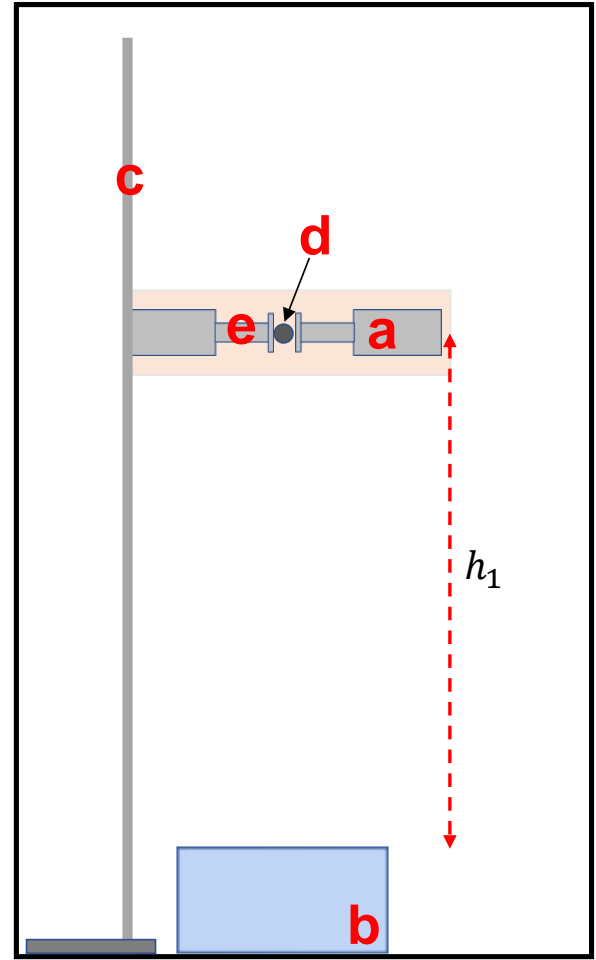

Figure 4. Schematic side view of the drop test apparatus a) Solenoids holding the particle b) Base block c) Cantilever pole to adjust the height of drop d) Test grain e) Plunger 


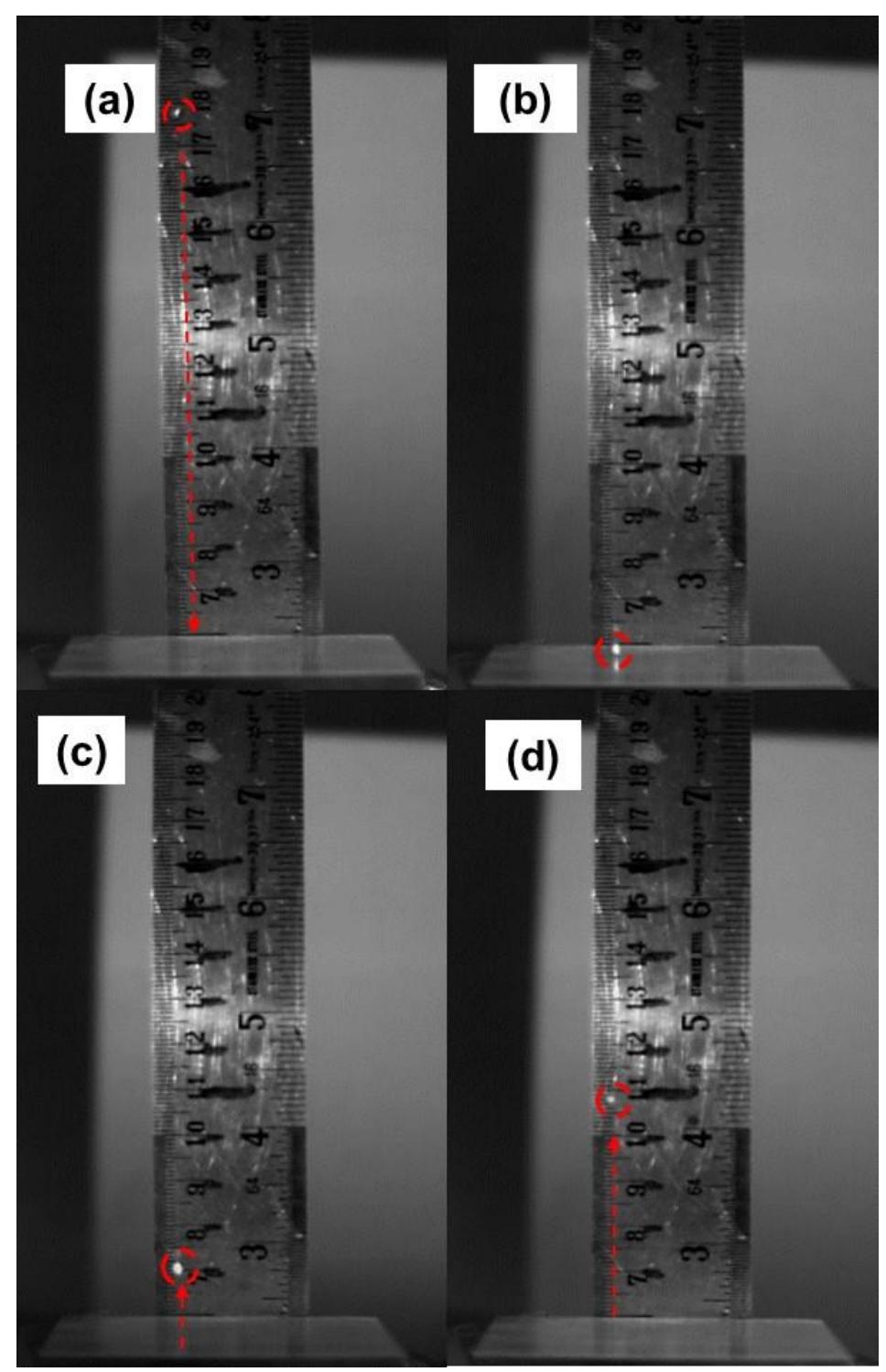

Figure 5. Various stages of chrome steel ball impacting on stainless steel surface (a) Initial path of drop (b) Impacting the surface of stainless steel (c\&d) Rebound path 


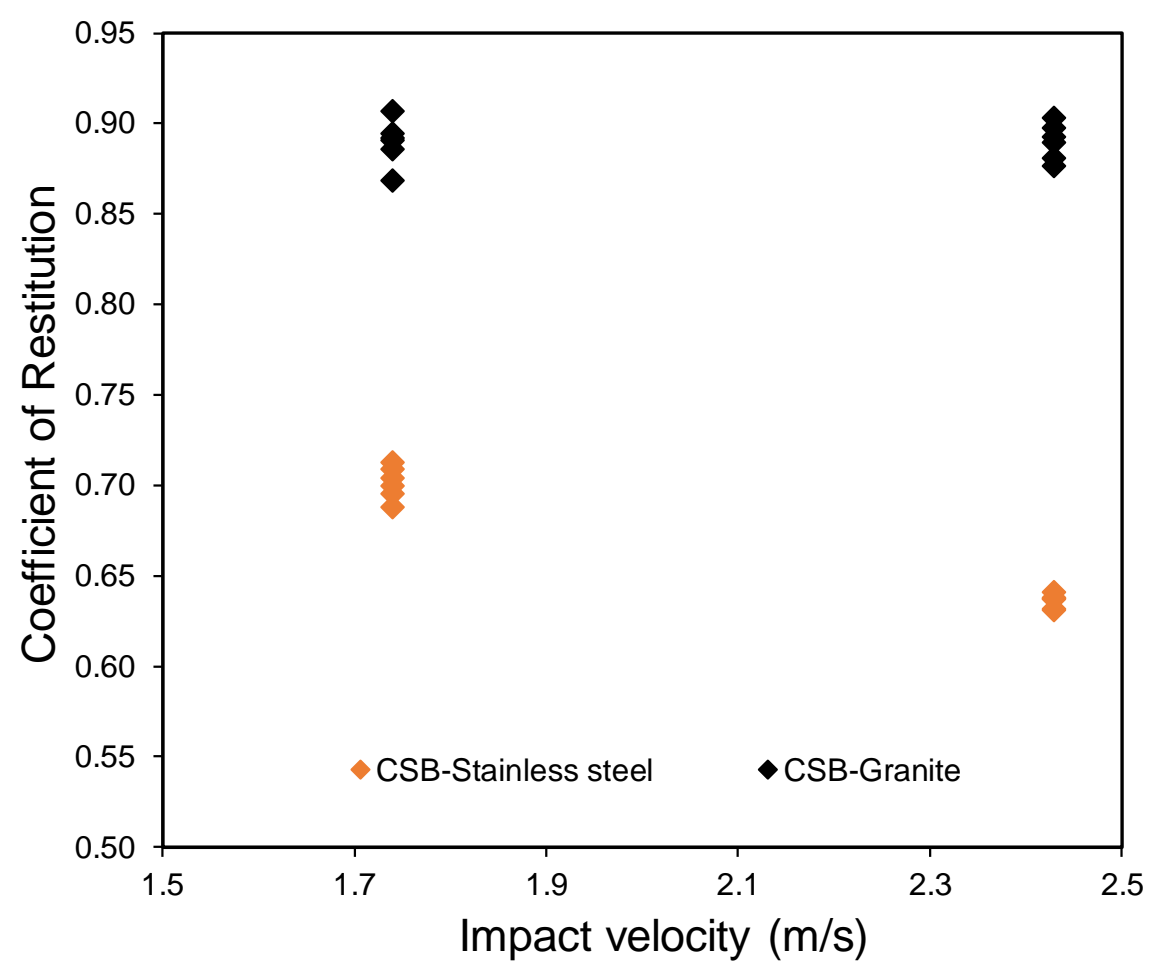

35

Figure 6: The repeatability of the coefficient of restitution values for CSB impacting on 37 stainless steel and granite blocks

38

39

40

41

42

43 


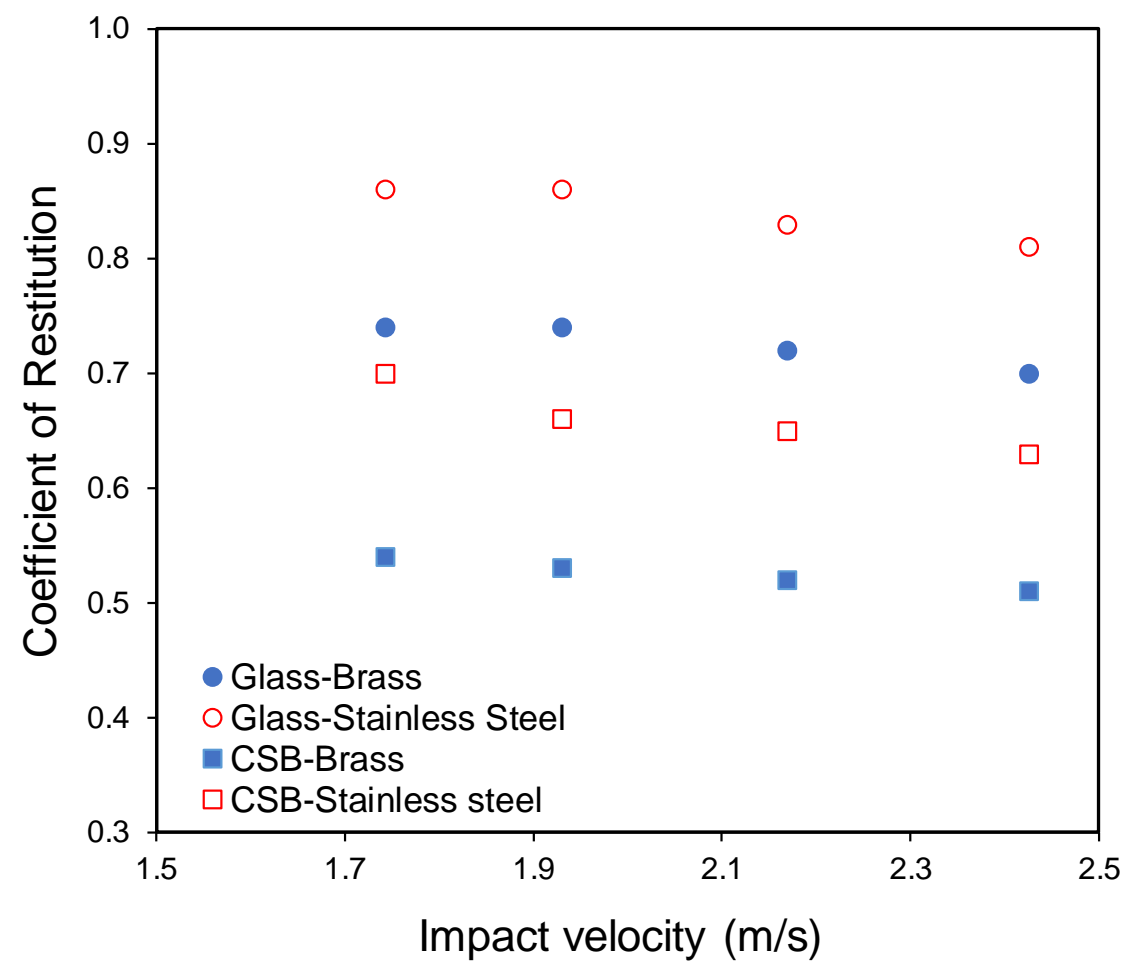

Figure 7: The coefficient of restitution against impact velocity for GB and CSB on brass and stainless steel blocks

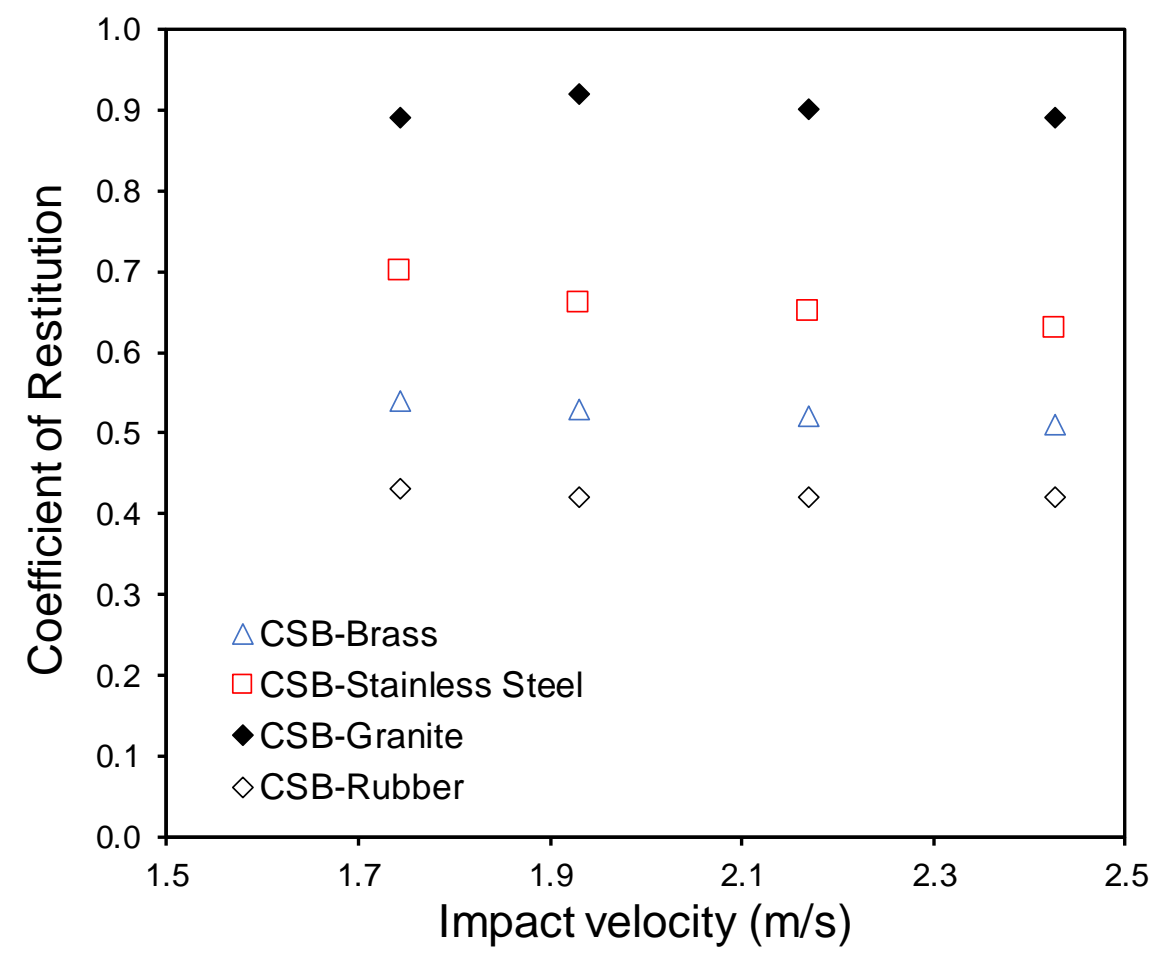

Figure 8: The coefficient of restitution against impact velocity for CSB on different base blocks 


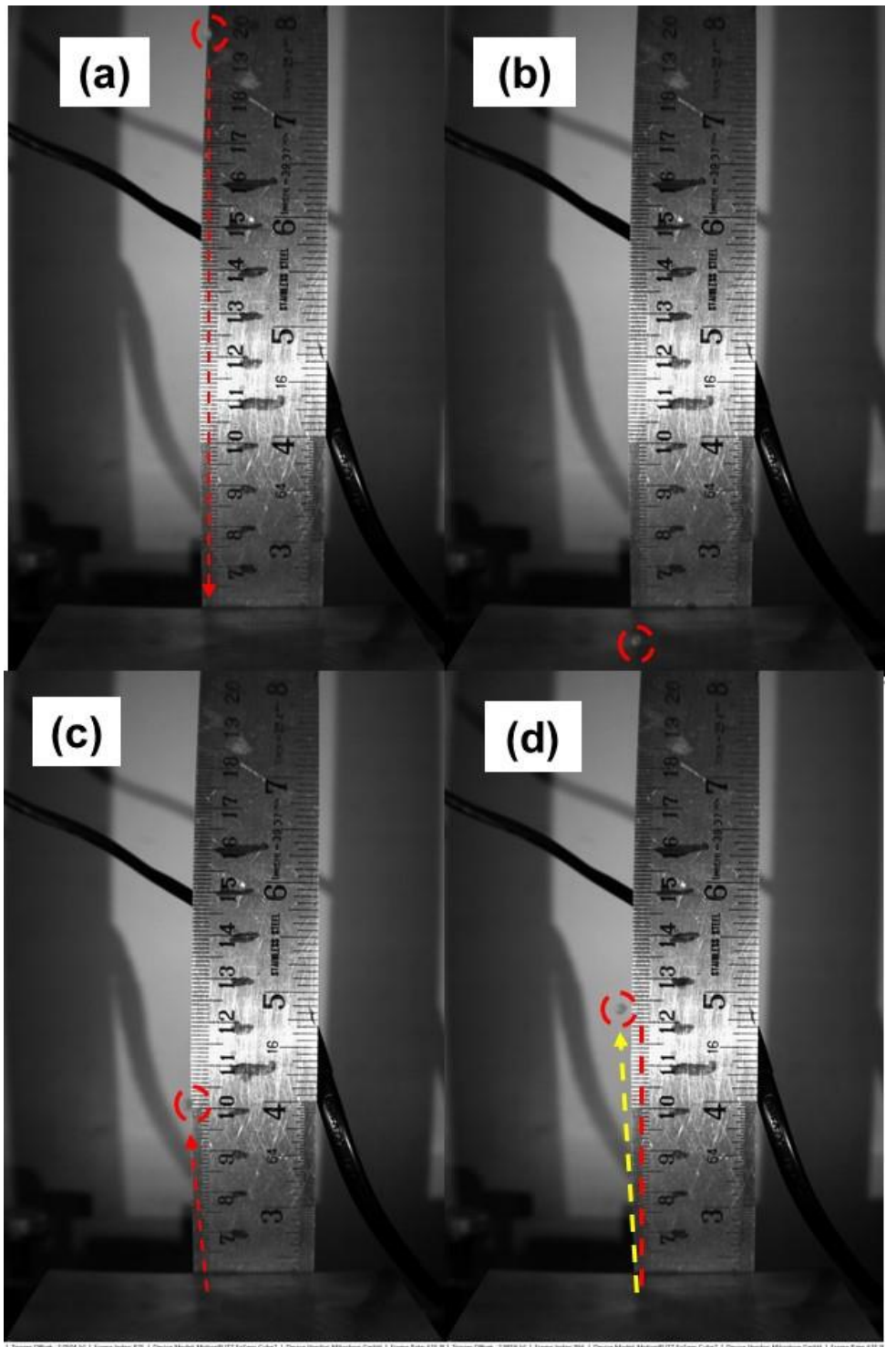

Figure 9. Various stages of LBS impacting on surface of brass block surface (a) Initial path of 55 drop (b) Impacting the surface of brass block (c\&d) Rebound path 
57

58 59

60

61

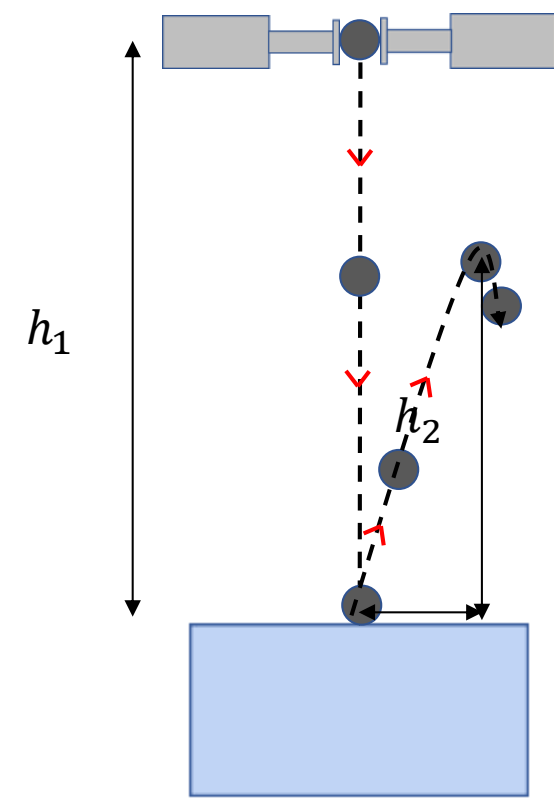

Figure 10. Schematic view of LBS grain impacting the base block and deviating from initial path of drop

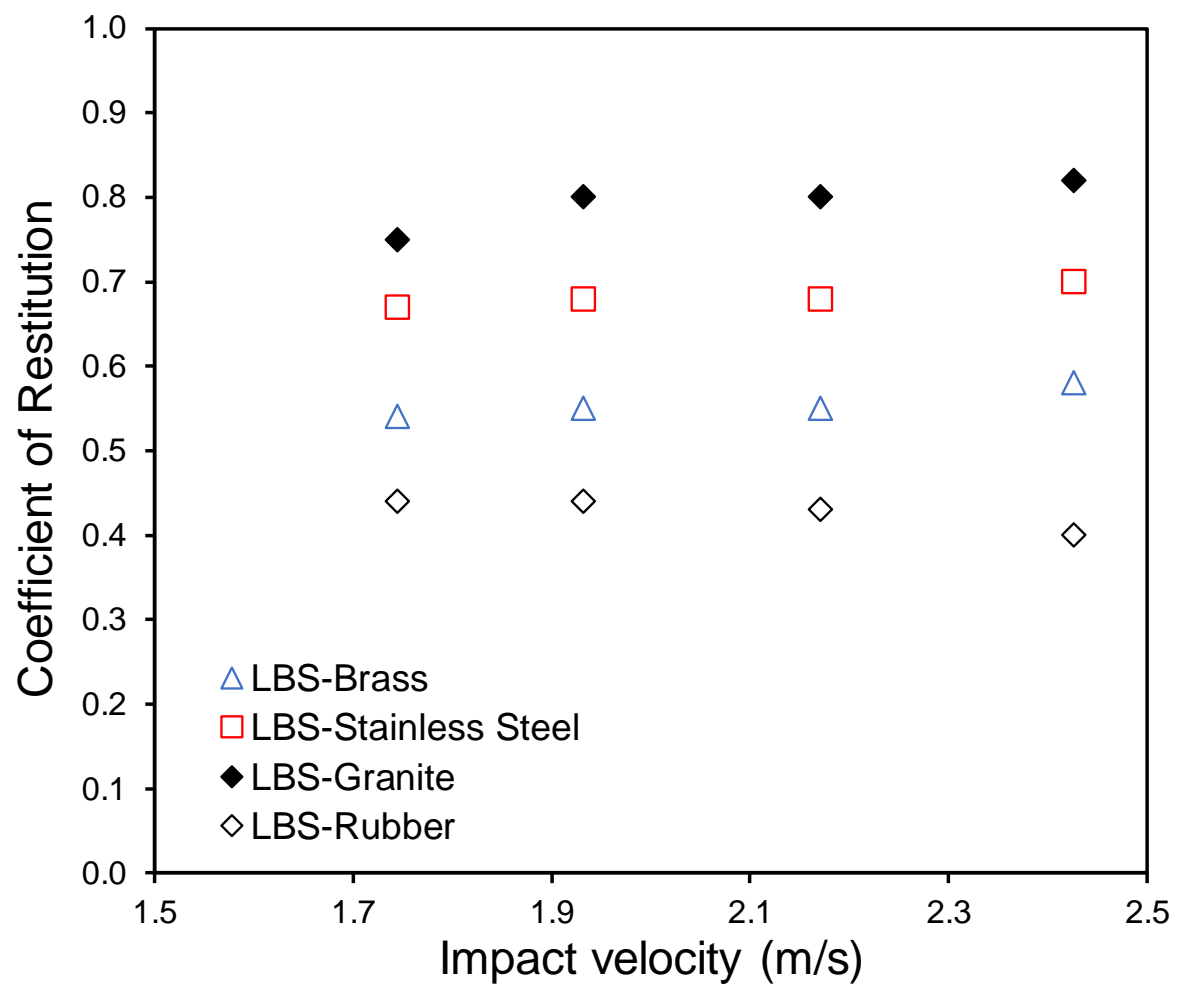

Figure 11. The coefficient of restitution against impact velocity for LBS on different base blocks 


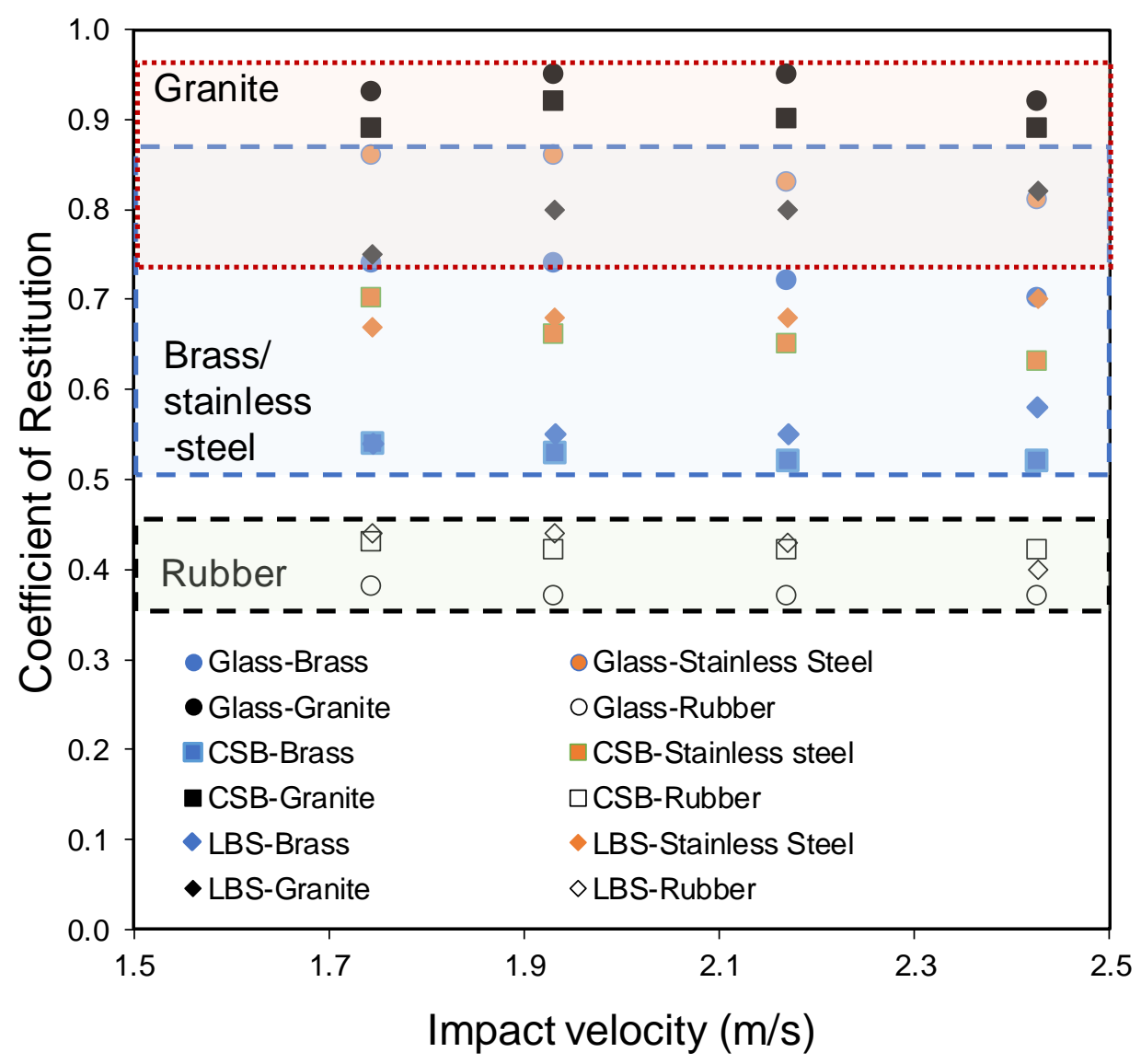

67

68 Figure 12. The average values of coefficient of restitution for all the grain and base block 69 combinations 


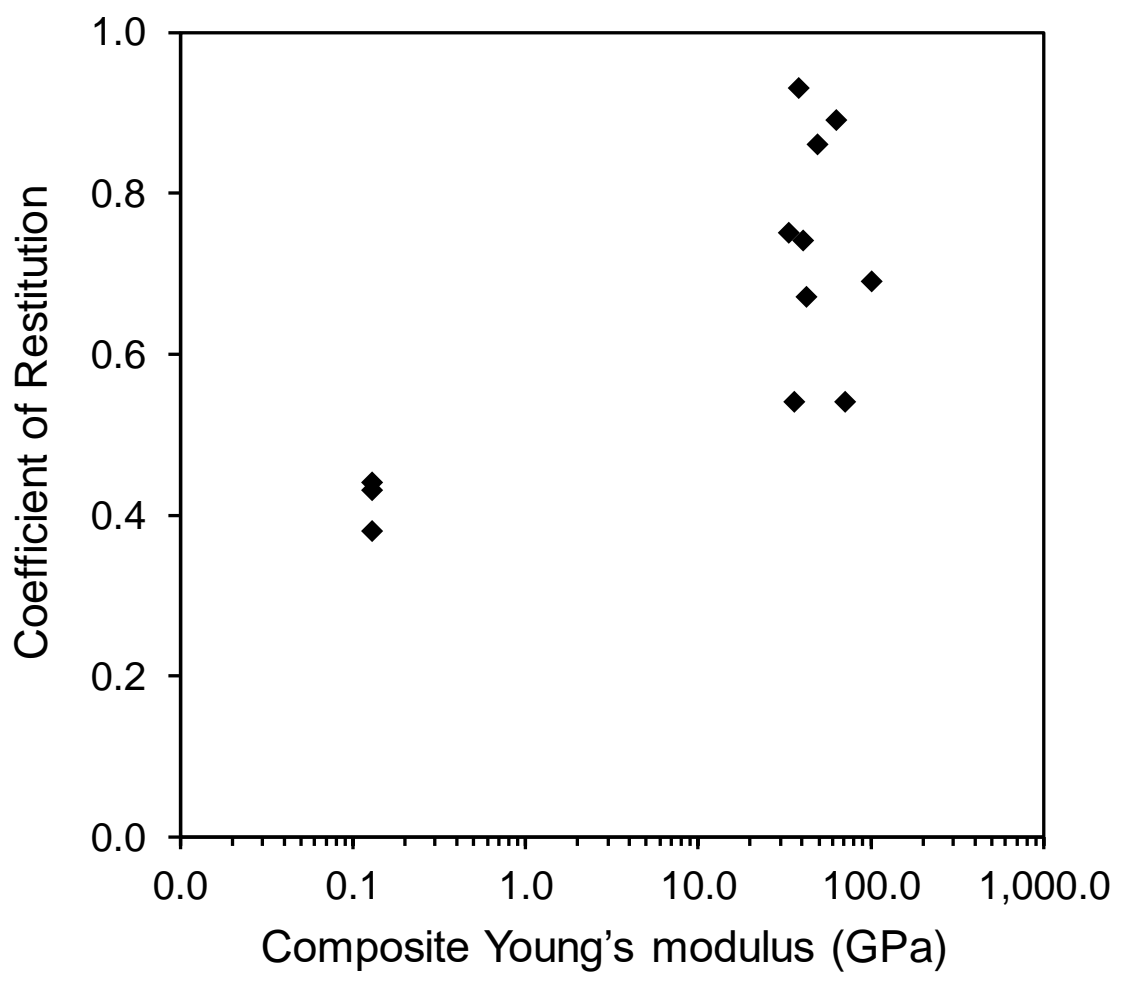

Figure 13. Variation of the average values of coefficient of restitution with composite Young's modulus of the grain and base block combinations (whole set of data)

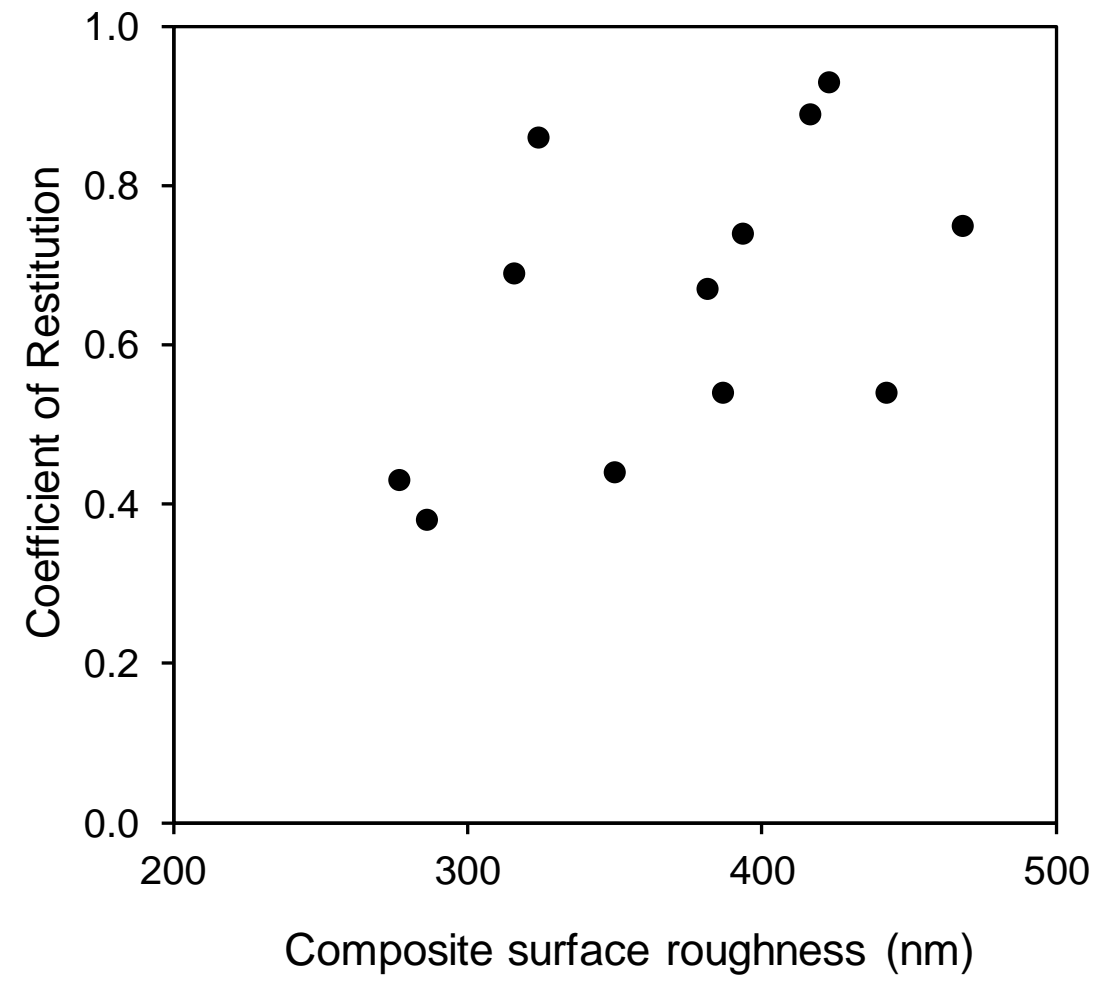




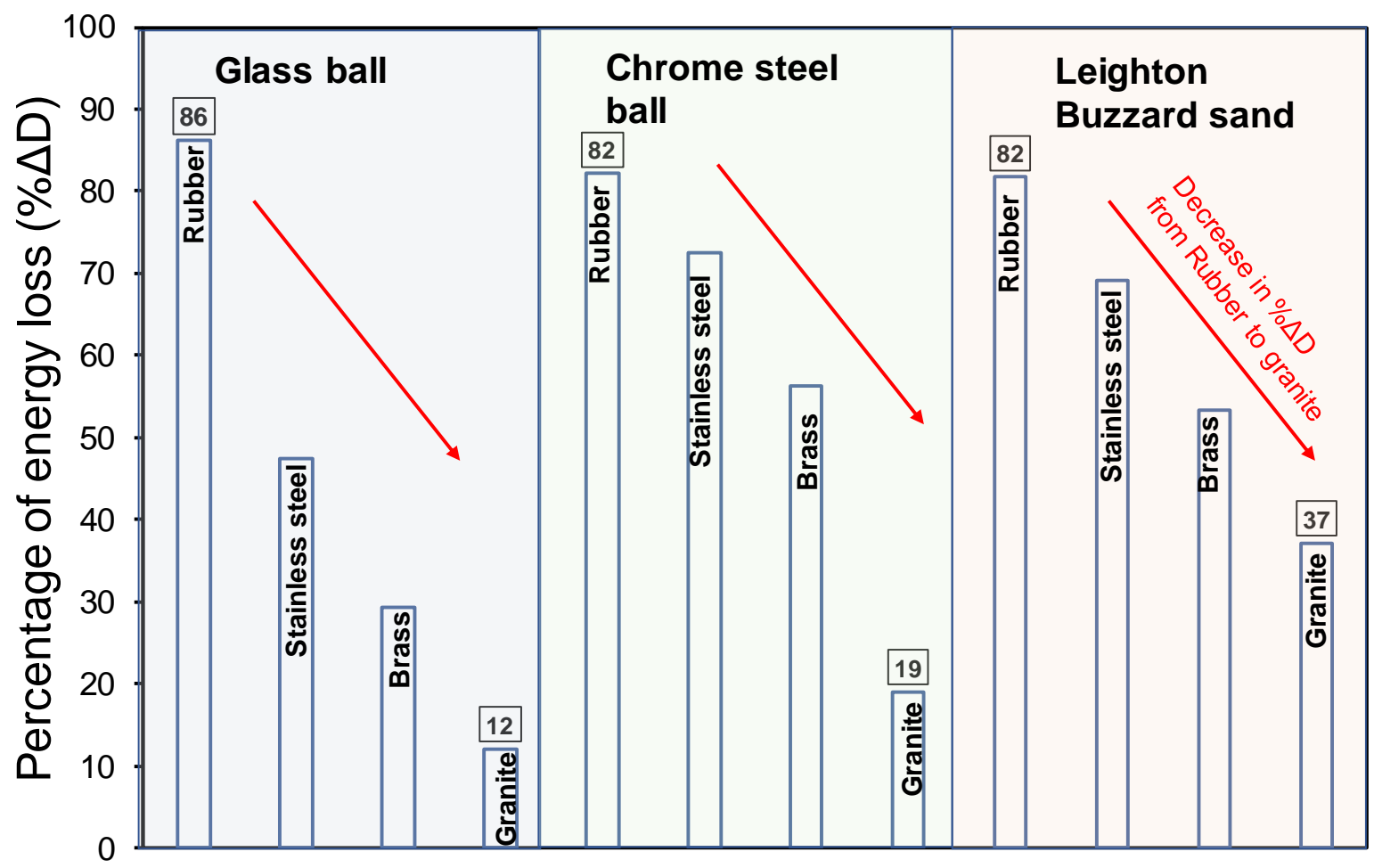

79

Figure 15. Histograms of average value of percentage energy loss for various grain and block combinations showing rubber and granite have the highest and lowest value of energy loss in all the tested combinations

83

84

